1 Performance profiles of metallic bridges subject to coating degradation and

2 atmospheric corrosion

3 Alexandros N. Kallias ${ }^{1}$, Boulent Imam ${ }^{2,{ }^{*}}$ and Marios K. Chryssanthopoulos ${ }^{3}$

4 Department of Civil \& Environmental Engineering, University of Surrey, Guildford, Surrey,

$5 \quad$ GU2 $7 X H, U K$.

6 (Email: ${ }^{1}$ alexandros.kallias@ gmail.com, ${ }^{2}$ b.imam@surrey.ac.uk, Tel.: +44 1483689679 ,

73 mkchry@surrey.ac.uk)

$8 *$ Corresponding author

9

10

11

12

13

14

15

16

17

18

19

20

21

22 


\section{atmospheric corrosion}

This study focuses on deterioration modelling and performance assessment of metallic bridges affected by atmospheric corrosion, considering also the contribution of typical protective systems in the form of multi-layer coatings. The mechanisms leading to coating degradation are reviewed and the main coating types used by infrastructure owners are highlighted. Building on information contained in industry manuals, a simple model for coating degradation is proposed. Atmospheric corrosion models are then presented, with emphasis given to exposure classification, in line with corrosivity classification guidelines and recent research quantifying the influence of corrosion through dose response functions. Coating degradation and corrosion models are integrated into a modelling framework, aimed at producing performance profiles of elements in metallic railway bridges. Finally, the framework is implemented in a case study in which a range of condition and resistance performance criteria are presented for different elements, such as girders or stiffeners, and their constituent parts, such as webs and flanges. It is shown that the proposed methodology is sufficiently detailed to enable differentiated performance predictions based on key external factors, and has scope for improvement, especially as coating and corrosion models are informed by the collection of field data.

keywords: performance profiles, corrosion, coatings, degradation, metallic bridges.

4 Nomenclature

$A$ is an empirical constant depending on exposure conditions ( $\mathrm{mm} / \mathrm{year})$

$6 \quad A_{0}$ is the uncorroded area

$4 A(t)$ is the corroded area

$8 A_{p r}(t)$ is the residual protected area of coated surface

$A_{p r 0}$ is the initial protected area of coated surface

$B$ is an empirical constant depending on exposure conditions

$1 C(t)$ is the uniform thickness loss $(\mathrm{mm})$

$52 \mathrm{Cl}$ is the (annual average) chloride deposition rate $\left(\mathrm{mg} / \mathrm{m}^{2} . \mathrm{d}\right)$ 
$53 f_{S t}$ is a function of $T$

$54 I_{0}$ is the uncorroded 2 nd moment of area about the relevant member axis (major/minor).

$55 I(t)$ is the corroded 2 nd moment of area about the relevant member axis (major/minor).

$56 \quad R_{A}(\mathrm{t})$ is the buckling ratio

$57 \quad R_{B}(t)$ is the bending resistance ratio

$58 R_{E B}(t)$ is the elastic buckling ratio

$59 R H$ is the average annual relative humidity $(\%)$

$60 R_{L B}(t)$ is the local buckling ratio

$61 R_{S}(t)$ is the shear resistance ratio

$62 S_{0}$ is the initial (uncorroded) value of section modulus

$63 \mathrm{SO}$ is the average annual deposition of $\mathrm{SO}_{2}\left(\mathrm{mg} / \mathrm{m}^{2} . \mathrm{d}\right)$

$64 \mathrm{SO}_{2}$ is the sulphur dioxide concentration $\left(\mu \mathrm{g} / \mathrm{m}^{3}\right)$

$65 S(t)$ is the time-varying (corroded) value of section modulus

$66 t$ is the time (years)

$67 \quad T$ is the (annual average) air temperature $\left({ }^{\circ} \mathrm{C}\right)$

$68 t_{f l, 0}$ is the uncorroded thicknesses of the compression flange (or any other element)

$69 t_{f l}(t)$ is the corroded thicknesses of the compression flange (or any other element)

$70 \quad T_{L}$ is the service life

71 TOW is the time of wetness (h/year)

$72 T_{U}$ is the time at which the coating is lost from the entire surface area

$73 t_{w 0}$ is the thickness of the uncorroded web element

$74 t_{w}(t)$ is the thickness of the corroded web element 


\section{Introduction}

According to an extensive demographic survey undertaken for the Sustainable Bridges project (Bell, 2007), more than 35\% of European railway bridges - whose total number is estimated to be well in excess of 300,000 - are over 100 years old. Although bridges of masonry construction are the single largest group within the overall population, metallic bridges - including those with steel/concrete or encased beam construction - comprise more than a third, with about one in five being centenarian. Steel and wrought iron are the predominant metals, with the latter having been used extensively in the 19th century until the era of steel began. In fact, more than 15,000 wrought iron bridges remain in service, mainly on the UK railway network, which had already expanded significantly by the time when steel was mass-produced. The same survey, which spanned railway authorities from Italy to Finland and from Poland to Ireland, revealed that the main asset management priorities relate to the improvement of the assessment process, with refined inspection/diagnosis tools and performance prediction also attracting significant attention.

Due to a large proportion of these bridges being on heavily utilized networks, large scale replacement is practically impossible, notwithstanding the worldwide financial constraints imposed on infrastructure maintenance budgets. Therefore, refined assessment methods and, where necessary, techniques that can improve prediction capability with respect to remaining service lives, thus allowing a life extension even by a modest fraction, are actively being sought. These refined methods could help in improving decision making related to asset management, and enable an orderly transition to the next generation of railway infrastructure. However, these decisions need to be taken in the context of aging and exposure to harsh environmental conditions, both of which contribute to wear and deterioration. In the case of metallic bridges, the former manifests itself through fatigue, whereas the latter is principally related to propensity to corrosion; either can have major 
101 implications on safety, functionality and appearance. This study focuses on corrosion, which

102 is a commonly observed cause of damage and failure in metallic bridges (Wardhana \&

103 Hadipriono, 2003, Imam \& Chryssanthopoulos, 2012).

104 The occurrence and the subsequent rate of progression of the various types of

105 corrosion depend on several factors and their interactions, with the majority associated with

106 exposure conditions and the type of protection system applied, though maintenance practices

107 also play a part. The progression of corrosion damage can lead to inadequate performance

108 and reduced safety, which ultimately can result in structural failures. However, even before

109 structural failure is reached, corrosion deterioration can be assessed as unacceptable on the

110 basis of condition criteria. In simple terms, corrosion can be classified as general or local,

111 though a more precise classification based on the forms of corrosion (e.g. Landolfo et al.,

112 2010) subdivides it into general (uniform), pitting (localised), crevice, erosion, galvanic and

113 fatigue corrosion. It should be noted that over time, a localised region can spread spatially or,

114 conversely, a uniform domain can develop local patterns, emphasizing the time-variant

115 complexities of the corrosion process.

116 Several studies have been carried out dealing with performance assessment of

117 deteriorating steel bridges (e.g. Kayser \& Nowak, 1989, Czarnecki \& Nowak, 2008, Sharifi

118 \& Paik, 2011). However, a systematic exposure classification is hitherto lacking, and

119 corrosion damage is predicted from models based on non-homogeneous databases, typically

120 associated with unqualified levels of uncertainty. Furthermore, in most studies the time-

121 dependent performance of the protective system, which needs to be broken down before

122 corrosion damage occurs on the metallic surface, has not been considered explicitly.

123 This paper focuses on deterioration modelling and performance assessment of

124 metallic bridges affected by atmospheric corrosion, considering also the contribution of

125 typical protective systems. Emphasis is given to exposure classification, in line with 
126 corrosivity classification guidelines and research aimed at quantifying the influence of

127 corrosion through dose response functions. A distinction is made between condition and

128 resistance based performance criteria, to suit various asset management objectives, which can

129 be addressed through a hierarchical modelling process depending on available information.

130 The proposed methodology is demonstrated using typical metallic bridge elements, for which

131 performance profiles are developed under different short- and long-term exposure scenarios.

\section{Deterioration modelling framework}

\subsection{Exposure classification}

134 Coating deterioration and steel corrosion (following the loss of protection provided by the coating) are time-variant processes, with their rate being determined by the outdoor exposure conditions experienced by the bridge. They can be broadly classified as: (a) immersed, (b)

137 splash zone and (c) atmospheric exposure. Each of these environments is associated with 138 different ranges of corrosivity potential. This study focuses on atmospheric corrosion, which can itself be subdivided in a number of categories, namely rural, urban, industrial/coastal exposures (Figure 1). Several studies (e.g. Feliu et al., 1993, Gascoyne \& Bottomley, 1995,

141 Klinesmith et al., 2007, BS EN ISO, 2012a) have concluded that the main parameters

142 influencing the atmosphere's corrosivity are climatic factors (i.e. relative humidity and

143 temperature) and atmospheric pollutants (i.e. sulphur dioxide $\mathrm{SO}_{2}$ and chlorides $\mathrm{Cl}^{-}$). $\mathrm{Physical}$ monitoring of these parameters could be used to determine the atmospheric corrosivity classification of a particular location.

The standard BS EN ISO 9223 (2012a) provides a framework for the classification of

147 atmospheric corrosivity based on the levels of the main influencing climatic and pollutant

148 variables. Specifically, in BS EN ISO 9223, the spectrum of atmospheric corrosivity is

149 divided into five categories varying from very low (category $\mathrm{C} 1$ ), corresponding to rural

150 environments, up to very high (C5) and extreme corrosivity (CX). In turn, the correlation of 
151 these exposure classifiers with metal loss measurements has allowed the development of corrosion models (discussed in section 2.3). Table 1 briefly describes each corrosivity category together with the expected ranges of corrosion rates within each category. In considering the deterioration of complex and spatially extended structural systems such as bridges, individual elements (e.g. deck, main girders, cross beams, etc.) are likely to experience dissimilar corrosion rates due to differences in the microclimate which develops in their immediate surroundings (Hutchins \& McKenzie, 1973). For instance, a Japanese survey has shown that external main girders of steel bridges are more susceptible to corrosion than inner girders (Tamakoshi et al., 2006).

\subsection{Protective coatings}

162 One of the aims of this study is to examine the performance of coatings applied onto metallic

163 surfaces of bridge components (BS EN ISO 12944). Several coating types - of varying

164 composition and performance - exist for the protection of structural steelwork, including organic, inorganic, metallic, duplex and hybrid systems (MAINLINE, 2014). In practice, the majority of the coating systems consist of several layers with each layer performing a different function. Organic, metallic and duplex (hybrid) coatings protect the substrate metal through the interface with the anodic and cathodic reactions in the cell and/or by hindering the transport of ions to the substrate surface. Based on their resistance mechanisms, coatings can be classified in the following groups (Greenfield \& Scantlebury, 2000, Hare 2006, de Wit et al., 2011):

- Barrier coatings, which suppress the diffusion of ions through the coating to the substrate surface.

- Inhibitive coatings, which promote the formation of an insoluble passive film on the metal substrate; careful selection of the binder and the inhibitive pigment is required to 
avoid the rapid exhaust of the inhibitive ions provided by the pigment and reduce blistering.

- Sacrificial coatings, which protect the substrate metal through the mechanism of galvanic corrosion; here, the metal powder in the coating becomes the anode while the

\subsubsection{Coating types}

182 This section highlights the compositions and performance characteristics of the main coating 183 types. Organic coating systems are built-up by several compatible layers, producing a wide 184 range of properties by varying the composition and thickness of the individual layers. The 185 main constituents of organic coating layers are the binder (usually an epoxy matrix), the pigment and the solvent, with the former determining the physical and chemical properties of the coating. Fillers and additives are commonly used to add specific properties to the final coating, such as impact and abrasion resistance, UV absorption, etc. (Keijman, 1999, de Wit et al., 2011). The first layer, placed in direct contact with the substrate metal, is the primer

190 which can be enriched with corrosion inhibitive pigments, e.g. galvanic pigments incorporating metallic zinc particles (Hare, 2006). The function of the topcoat (or finish) layer is to provide initial resistance against the external environment and determine the aesthetic appearance (e.g. colour). structures subjected to a range of harsh exposure conditions (e.g. marine environments). These coatings protect the substrate metal through sacrificial cathodic protection together with barrier action. The metallic coating, typically zinc in hot-dip galvanizing or aluminium in thermal sprayed coatings, acts as the anode of an electrochemical cell (CORUS, 2004). In thermal spraying applications, a heated spray gun (oxygas flame or electric arc) is fed with the metals (powder or wire form) and the melted metal is blown onto the metallic surface 
using a compressed air jet (CORUS, 2004). Suitable surface preparation facilitates the mechanical bond between the coating and the substrate metal. Guidance on the use of thermal spraying aluminium/zinc coatings can be found in BS EN 22063.

Duplex (metallic-organic layers) and hybrid (metallic-metallic layers) coating systems provide superior long-term corrosion protection. Typically, duplex coating systems consist of a metallic coating applied directly on the prepared substrate metal followed by subsequent organic coating layers. In this way, the pores of the metallic coating are sealed using the organic coating, adding a barrier against the ingress of corrosive species. In general, the main drawback of duplex and hybrid coating systems is their relatively higher initial cost; often this can be offset by the anticipated reduced need for both maintenance/repair and minimised service disruption. Hybrid coatings systems, consisting of metal alloys or two dissimilar metallic coating layers, have also been formulated. The results of Kuroda et al. (2006) from a long-term experimental program using thermally sprayed and hybrid Zinc-Aluminium alloy coatings showed that these coatings performed well in marine environments even when unsealed. Similar results were obtained by Salas et al. (2012) using a thermally spayed twolayer Zinc-Aluminium hybrid coating system, with the Zinc layer applied as a primer.

\subsubsection{Coating deterioration}

Deterioration of in-service coatings is affected by several factors including coating specification, quality of the application (surface preparation, application, curing), the environmental exposure conditions and accidental damage. Clearly, the large number of variables, together with their possible interactions, makes coating deterioration a complex phenomenon. In general, the presence of defects within a coating system accelerates the deterioration process which eventually leads to coating failure. The most common failure mode is loss of adhesion, for instance due to blistering or cathodic delamination of the coating. Other coating failure criteria include the time needed for the consumption of the 
active ingredients of inhibitive and sacrificial coatings (i.e. inhibitive pigment, consumption of zinc dust, etc.), though the actual time-to-failure is highly uncertain due to the variability in surface preparation, coating application quality, the constantly changing exposure conditions, inherent defects, as well as unexpected factors such as accidental damage. Further information on defects and failure modes of protective coatings can be found elsewhere (e.g. Greenfield \& Scantlebury, 2000, Sorensen et al., 2009). Cathodic delamination is a commonly observed failure mode of organic coatings caused by inherent or induced defects. Corrosion initiates at the defect, forming corrosion products which potentially block the pores. As a result, the area where the coating is damaged becomes the anode while cathodes develop at the edges of the defect. The alkaline environment ( $\mathrm{pH}>12$ due to hydroxyl ions) at the cathodic areas of the substrate is responsible for bond loss at the coating-substrate interface, with the formation of insoluble corrosion products promoting the separation of anodes and cathodes. The rate controlling parameter in this failure mechanism is the diffusion rate of cations required for charge neutralization of the cathodically produced hydroxyl ions.

Blisters are typically associated with coatings where no defect is visible. The possible mechanisms involved in this type of failure include expansion due to swelling, gas inclusion or osmotic processes (Sorensen et al., 2009). Among these mechanisms, osmotic processes

244 have been shown to be the most significant in promoting blistering. Greenfield \& Scantlebury 245 (2000) have studied the development of blisters, which have been classified as osmotic, 246 anodic and cathodic.

\subsubsection{Coating selection}

248 In the United Kingdom, corrosion protection of railway bridges using coatings and sealants is

249 covered by guidance documents produced by the infrastructure owner. Current

250 recommendations distinguish between new and existing steelwork, with a number of coating 
systems recommended for each category (see NR 2009a, b \& c). Commonly used coatings for new construction include duplex systems in which the first of several layers is a metallic coating, for instance thermally sprayed zinc or aluminium. On the other hand, coating systems for maintenance of existing structures are broadly subdivided into those recommended for patch repairs (bitumen based) and those for complete re-application. These protective systems typically consist of several layers applied sequentially on the treated steel surface. As mentioned above, the performance of a coating system is influenced by several factors, including the composition and exposure conditions, as well as workmanship and quality control during application. For example, Table 2 summarises the characteristics and expected service life of two coatings used in railway maintenance. Guiding values for the expected service life for other coating systems currently used are given in the aforementioned manuals (NR 2009a, b and c). It is also recommended that the selection of a suitable protective system be related to the anticipated exposure conditions (e.g. classification of exposure conditions based on BS EN ISO 12944-2).

\subsubsection{Coating deterioration modelling}

267 In general, the development of models to predict coating performance requires direct or 268 indirect consideration of the following parameters:

- The coating's chemical and physical characteristics, including its principal resistance mechanism (e.g. barrier, inhibitive or galvanic action).

- The anticipated exposure conditions, including levels of individual climatic and atmospheric variables for a particular location.

- Other aspects such as the quality of surface preparation, operator's skills and experience, and coating curing characteristics. 
Thus, modelling of coating performance can be attempted at different levels of complexity and accuracy, as outlined below:

- In Level 1 models, either a single value or a range is available for the expected service 
assumes that the application of the coating is carried out by competent coating contractors, and, hence, the possibility of rapid deterioration and/or premature peeling are minimised. Furthermore, the results of Itoh and Kim indicate that coating deterioration tends to be nonlinear over time, as schematically depicted in Figure 2. This is further supported by a study on the quality of steel bridge coatings (Chang et al., 2000) in which non-linear deterioration curves similar to those shown in Figure 2 are proposed based on the relationship between warranty period and expected service life. Building on these idealisations, a polynomial relationship is proposed, assuming that service life $\left(T_{L}\right)$ estimates quoted in industry manuals correspond to circa $50 \%$ of a coated surface being unprotected at time $T_{L}$ :

$$
\frac{A_{p r}(t)}{A_{p r 0}}=1-\left(\frac{0.6 t^{2}}{T_{L}{ }^{2}}-\frac{0.1 t}{T_{L}}\right)
$$

where $A_{p r}(t)$ and $A_{p r}$ are the residual and initial protected areas respectively and $t$ is the time in years. This equation may be used to predict the time $T_{U}$ at which the coating is lost from the entire surface area. Note that $A_{p r}(t) \leq A_{p r 0}$ for all $t$ and $A_{p r}(t)=0$ for $t>T_{U}$.

314 proposed polynomial leads to $T_{U}=1.38 T_{L}$. Given the observed trends in experimental and

315 field studies, this is a first attempt at a coating performance model, which can be used to 316 estimate deterioration over any given surface (e.g. a web or a flange of a plate girder), for 317 situations where the deterioration is likely to become progressively more extended. It should 318 be noted that the coefficients in Equation (1) could be adjusted to reflect alternative values 319 regarding the percentage coating loss taken as the criterion estimating expected service life.

320 In general, such a model should consider coating performance not only at a particular 321 location but also its spatial characteristics. To enable this, information on whether uniform or localised corrosion is likely to be developed on a particular member should also be utilised. 


\subsection{Atmospheric corrosion models}

325 At a specimen scale, the progression of atmospheric corrosion in any given environment can

326 be modelled in terms of thickness loss over an exposed surface area. Over the years, models

327 of varying complexity and accuracy have been developed, as summarised in Table 3 . The proposed classification accords with that adopted for coating deterioration in section 2.2.4.

Haagenrud \& Henriksen, 1996) given by:

$$
C(t)=A t^{B}
$$

where, $C(t)$ is the uniform (measured as average over relatively small specimen surface areas) thickness loss (mm) after an exposure period of $t$ years and coefficients $A(\mathrm{~mm} / \mathrm{year})$ and $B$ (unitless) are empirical constants, obtained using regression analysis on physical test results grouped according to different atmospheric exposure conditions. This implies that the dependency on the exposure conditions and material type (e.g. type of steel) is captured implicitly using suitable values for coefficients $A$ and $B$, where $A$ represents the corrosion loss at the end of the first year and $B$ controls the rate of loss in subsequent years. Recommended values for $A$ and $B$ are generally deemed to exhibit high uncertainty, partly as a result of databases in which exposure conditions were poorly defined/grouped. It has also been suggested that Equation (2) is suitable for periods up to 20 years; for $t>20$ years,

342 thickness loss may be calculated using the linear relationship presented below (BS EN ISO,

343 2012b).

$$
C(t>20)=A\left[20^{B}+B\left(20^{B-1}\right)(t-20)\right]
$$

Figure 3 shows the thickness loss over time, for different corrosivity categories, predicted using Equations (2) and (3), with coefficients $A$ and $B$ chosen as either mid-range or 
corrosion losses are less than about $0.5 \mathrm{~mm}$ over a 30 year period, if no protective system is applied. On the other hand, much higher losses (more than twofold) are predicted for corrosivity category $\mathrm{C} 5$. The range in the values of the empirical coefficients $A$ and $B$, indicative of the inherent uncertainty, can also be seen to affect the predicted losses. Level 2 models offer the opportunity to relate directly the environmental and atmospheric pollutant variables to the rate of corrosion, instead of pooling the influence of all factors on empirical model constants. With the availability of data pertaining to environmental variables and/or atmospheric pollutant concentrations increasing (partly as a result of raised concerns over air quality in many urban/industrial areas), these more advanced models could, in future, offer refined corrosion predictions, potentially also allowing changes in input variables over time to be accommodated. An example of a relationship, which can be used to estimate coefficient $A$ in Equation (2) as a function of several environmental and atmospheric pollutant variables, leading to a Level 2 corrosion model, is given in BS EN ISO (2012a):

$$
A=1.77 S O^{0.52} \exp \left(0.02 R H+f_{S t}\right)+0.102 C l^{0.62} \exp (0.033 R H+0.04 T)
$$

where $S O$ is the average annual deposition of $\mathrm{SO}_{2}(\mathrm{mg} / \mathrm{m} 2 . \mathrm{d}), \mathrm{RH}$ is the average annual relative humidity (\%), $C l$ is the average annual deposition of $\mathrm{Cl}^{-}\left(\mathrm{mg} / \mathrm{m}^{2} . \mathrm{d}\right), T$ is the annual (average) temperature $\left({ }^{\circ} \mathrm{C}\right)$ and $f_{S t}$ is a function of $T$.

$$
C(t)=A^{\prime}\left(\frac{T O W}{C_{1}}\right)^{D}\left(1+\frac{S O_{2}}{E}\right)^{F}\left(1+\frac{C l}{G}\right)^{H} e^{J\left(T+T_{0}\right)} t^{B}=A_{K L} t^{B}
$$
where TOW is the time of wetness (h/year), $\mathrm{SO}_{2}$ is the sulphur dioxide concentration $\left(\mu \mathrm{g} / \mathrm{m}^{3}\right)$, $\mathrm{Cl}$ is the chloride deposition rate $\left(\mathrm{mg} / \mathrm{m}^{2} . \mathrm{d}\right), C_{1}=3800 \mathrm{~h} /$ year (mean value), $E=$ mean of measured values of $\mathrm{SO}_{2}, T$ is the air temperature $\left({ }^{\circ} \mathrm{C}\right)$, and $T_{0}=20{ }^{\circ} \mathrm{C}$. For flat carbon steel specimens (Klinesmith et al., 2007): $A^{\prime}=13.4, B=0.98, D=0.46, F=0.62, H=0.34$ and $J=$ 
372 0.016. Comparing Equations (4) and (5), it can be observed that both models retain the exponential term $\left(t^{B}\right)$ but differ in the modelling approach for the corrosion loss in the first year (represented by the remaining part of the function).

Figures 4(a) to 4(d) presents a sensitivity analysis on the effect of different climatic and atmospheric variables on the long-term predictions of corrosion thickness losses calculated using Equation (5). For the variables involved, typical values are used, as suggested in BS EN ISO (2012a). As can be seen, airborne salinity and $\mathrm{SO}_{2}$ concentration have the greatest impact on the long-term rate of corrosion. changes to exposure conditions over longer time horizons. These may be associated with initiatives to reduce atmospheric pollution in specific regions or related to effects brought about by climate change. For this purpose, equation (3), which is recommended for estimating losses beyond 20 years, is re-cast in the following form:

$$
C(t>20)=A \cdot 20^{B}+A \cdot B\left(20^{B-1}\right)(t-20)=C(t=20)+\frac{d C(t)}{d t}(t-20)
$$

where the first term represents the thickness loss due to corrosion over 20 years and the second term is the thickness loss from 20 years onwards. As can be seen, the first term (accounting for corrosion up to $t=20$ ) is of exponential form, whereas the second term (accounting for corrosion when $t>20$ ) is linear with a slope equal to $d C(t) / d t=A \cdot B\left(20^{B-1}\right)$. In the case where there is a change in exposure conditions at a time $t>20$ years, the slope of the linear portion $d C(t) / d t$ can be modified accordingly, by defining a new $A_{i}$ coefficient, to account for the new exposure conditions. Thus, for $n$ changes of exposure conditions beyond $t=20$ years, the following expression may be used:

$$
C(t>20)=C(t=20)+\sum_{i=1}^{n} \frac{d C_{i}(t)}{d t} T_{i}
$$


Figure 5 shows the corrosion loss predictions for two scenarios assuming atmospheric

397 pollution levels in a specific area are reduced, together with a no-change case. The first

398 scenario assumes a sharp reduction in the $\mathrm{SO}_{2}$ concentration at year 20 from 250 to 125

$399 \mu \mathrm{g} / \mathrm{m}^{3}$, whereas in the second scenario this reduction takes place gradually between year 20

400 and 40. Both emission reduction scenarios can be seen to result in lower thickness losses,

401 circa 1 to $1.5 \mathrm{~mm}$, compared to the no-change case. Note that the lines for reduced emission

402 scenarios become parallel after year 40, since the pollutants converge to the same level.

\section{Performance assessment}

404 The consequences of deterioration on metallic bridge elements can vary from aesthetic and

405 non-structural issues to progressive weakening and catastrophic failures (Prucz \& Kulicki,

406 1998). In the context of maintenance regimes, the former are addressed through condition

407 surveys, whereas the latter necessitate structural assessments. In this section, the coating and

408 corrosion models presented above are, first, combined so as to provide predictions of coating

409 and material loss under different exposure conditions (condition-based maintenance) and,

410 secondly, integrated within strength formulations relevant to different limit states, such as

411 tension, compression, bending and shear (capacity-based maintenance).

412 In general, environmental exposure leads initially to a breakdown and loss of coating

413 over a growing number and extent of surface spots, and, while this process is continuing,

414 corrosion also begins to take place in the least protected and more vulnerable spots. As

415 previously mentioned, the progression of deterioration will be influenced significantly by the

416 type of coating and substrate material, the presence of pollutants, bacteria and micro-climate

417 effects regarding temperature, humidity, wind direction, exposure to sunlight etc. Hence,

418 prediction of deterioration rates will be characterised by uncertainty and complexity at

419 different scales. In this respect, the proposed modelling approach cannot predict accurately

420 the deterioration of a single structure unless it is combined with inspection outcomes, which 
421 is beyond the scope of the present study. Nevertheless, it can provide an insight into median trends that may be observed over time in cohorts of similar structures.

Figure 6 shows schematically the proposed modelling approach for performance assessment. The coating performance is captured via Equation (1), with the service life, $T_{L}$, estimated based on information on particular coatings, e.g. as found in maintenance manuals. In estimating $T_{L}$ the factors shown in Figure 6(a), (specification, application quality, exposure) should, where possible, be taken into account. Material loss due to corrosion will then start at different points in time on the exposed surface, as shown in Figure 6(b); for this part, either Level 1 (Equation (2)) or Level 2 (Equations (4) or (5)) corrosion models may be used, depending on available information on exposure conditions.

The loss of thickness due to corrosion over any particular surface of a single member (e.g. web or flange plates in Figure 6(b)) will have an impact on the available cross-sectional area, which, in turn, influences other section properties relevant to different limit states ((bending, compression, etc.), e.g. the second moment of area or the radius of gyration. Thinning of the web or flange plate can also affect adversely local buckling strength, which is typically a function of the member slenderness, e.g. the flange half-width over thickness ratio. Moreover, if corrosion is allowed to progress considerably over an entire structure, overall load distribution may be affected, due to changes in members' axial and bending stiffness. Following the approach suggested by Prucz and Kulicki (1998), a number of residual resistance factors are proposed in the following, covering the principal limit states encountered in structural assessments of girder and truss bridges. Thus, for a bending limit state, this factor is given by

$$
R_{B}(t)=\left[\frac{S(t)}{S_{0}}\right]
$$

where, $R_{B}(t)$ is the bending resistance ratio, $S_{0}$ and $S(t)$ are the initial (uncorroded) and the time-varying (corroded) values of section modulus respectively. Depending on the class of 
446 the section (i.e. whether the elastic or plastic bending capacity can be reached), either the

447 elastic or plastic section modulus would have to be considered (BS EN 1993-1-1, 2005).

448 Clearly, for the calculation of the section modulus at time $t$, the distribution of the induced

449 corrosion damage across the section needs to be idealised; here, unless specific scenarios

450 based on micro-climate effects are considered, the baseline assumption is that the loss of

451 material is spread uniformly across the width of the flanges and along the web depth.

452 However, it is possible to adapt this equation to reflect the situation (sometimes observed in

453 real cases) where the bottom flange suffers more than the top flange due to local water

454 entrapment, bird fouling, etc.

455 If shear capacity is of concern, the corresponding ratio is given by

456

$$
R_{S}(t)=\left[\frac{t_{w}(t)}{t_{w 0}}\right]
$$

where $R_{S}(t)$ is the shear resistance ratio and $t_{w 0}$ and $t_{w}(t)$ are the thicknesses of the uncorroded and corroded web elements respectively.

Instabilities may be an issue either in the form of member (Euler) buckling or in the

460 form of local buckling, e.g. in flange outstands or slender webs. For member buckling, two ratios are relevant, depending on whether the member falls in a stocky or slender category.

For the former, the cross-sectional area becomes the controlling geometric property since material failure precedes buckling, thus the buckling ratio becomes

$$
R_{A}(t)=\left[\frac{A(t)}{A_{0}}\right]
$$

with $A_{0}$ and $A(t)$ being the uncorroded and corroded areas. For slender members in compression governed by elastic buckling, the ratio changes to

$$
R_{E B}(t)=\left[\frac{I(t)}{I_{0}}\right]
$$



formulae (Timoshenko, 1964), is proportional to the square of the thickness, and therefore, an appropriate local buckling ratio is given by

$$
R_{L B}(t)=\left[\frac{t_{f l}(t)}{t_{f l, 0}}\right]^{2}
$$

473

where, $t_{f l, 0}$ and $t_{f l}(t)$ are the thicknesses of the compression flange (or any other element). Finally, it is worth noting that for members under tension, the capacity is once more governed by the cross-sectional area and the relevant ratio is, thus, given by Equation (10).

\section{Case study}

Following the performance modelling framework presented in the preceding section, performance profiles are presented for members of a short-span (half-through) railway bridge with a span of 9.6m, as shown in Figure 7, located in a heavily polluted industrial site (C5 corrosivity classification as per Table 2). The examined bridge, which is typical on the UK railway network, consists of different member types, including external/internal main girders, stringers and cross-beams. The external main girders have $13 \mathrm{~mm}$ thick top and bottom flanges and $10 \mathrm{~mm}$ thick webs, with the overall height of the section being $1220 \mathrm{~mm}$. The yield strength of the material is taken as $f_{y}=300 \mathrm{MPa}$. It is further assumed that a protective coating is applied initially but no coating re-application takes place during the examined 30year maintenance planning window. However, the framework can also be used for an uncoated structure to focus on the effect of the coating on the structural performance, as well as to include the effect of coating re-application within a given maintenance period.

As often observed in inspections, the actual position of the bridge members (i.e. internal/external) can influence the aggressiveness of the micro-climate to which their metal surfaces are exposed. In one such scenario, the exposure conditions faced by internal members are less harsh compared to external members: thus, whereas the global exposure 
493 classification matches the microclimate of external members, internal members (e.g.

494 stringers) are exposed to micro-climates of lower aggressiveness. As mentioned previously,

495 this assumption can be further refined, should particular factors prevail that may distinguish

496 sub-elements of a girder, either in a vertical direction (e.g. top vs. bottom flange) or

497 horizontally (e.g. end vs. middle sections). Table 4 lists the scenarios for which performance

498 profiles are developed. The service life of the coatings $\left(T_{L}\right)$ is taken as the mid-range of the

499 values given in Table 2. In view of the bridge type, bending, shear and local buckling limit

500 states are considered for different members. In particular, overall bending and shear are

501 examined for the internal and external girders, whereas local buckling is assessed for the

502 compression flange of the same members. For completeness, other members (e.g. cross-

503 girders, longitudinal stiffeners) could also be included, bearing in mind the particular limit

504 states that may govern their performance.

\section{$505 \quad 5$ Results and discussion}

506 In this section the results obtained from the case study which illustrate the methodology are

507 presented and discussed in relation to the observed performance for different coating types,

508 exposure conditions and location of different elements within a typical metallic railway

509 bridge. Combining condition-based indicators (e.g. \% area of coating breakdown) with the

510 evolution of structural resistance can be a useful tool within the context of asset management.

511 Specifically, understanding the effect of different exposure conditions on the expected

512 evolution of condition and/or resistance over time would allow the optimisation of resource

513 allocation and justify the prioritisation of future examinations and assessments, whilst

514 maintaining the overall risk associated with a bridge portfolio at tolerable levels. 


\section{5.1.1 Coating performance}

518 Figure 8 shows the evolution of coating performance predicted using Equation (1) for two

519 coating systems subjected to two different atmospheric exposure conditions. The results

520 indicate that for all cases examined, an initial period exists during which the coating remains

521 intact, irrespective of the exposure conditions. However, the higher performance coating M21

522 is associated with a much longer period during which it remains fully effective; in fact almost

523 double the period estimated for the M27.4 coating. Moreover, the effect of different exposure

524 conditions becomes quite significant beyond this initial post-application period. For example,

525 for coating M27.4, it can be seen that when $50 \%$ of the substrate metal area is unprotected

526 under C3 exposure conditions while only approx. $25 \%$ of the area remains protected when

527 considering the C5 environment. Such results can be used to facilitate decision making within

528 the context of long term maintenance and whole life cost assessment (MAINLINE, 2013c).

529 To this end, the collection of field data from regular inspections would allow the

530 improvement of coating deterioration models, whereas simultaneous recording of the

531 geographical locations would facilitate estimation of statistical properties. At present,

532 although inspection data is being routinely collected, there is no attempt to correlate these

533 with atmospheric conditions or positioning data, which hinders model development.

\section{$534 \quad$ 5.1.2 Thickness losses}

535 Figures 9(a) and 9(b) show the predicted flange thickness and web losses over time for

536 external girders (EMG) subjected to C5 exposure conditions. In all cases, an initial period

537 exists during which coatings are fully effective and no thickness loss is recorded. Thereafter,

538 gradual breakdown of the coating leads to thickness loss over time with the rate of thickness

539 loss being a function of several environmental and pollution-related variables (e.g.

540 temperature, humidity, $\mathrm{SO} 2, \mathrm{Cl}$ ). As previously discussed, their effect is collectively 
541 expressed through a particular set of $A$ and $B$ coefficients. In Figures 9(a) and 9(b), results are

542 also shown for the case where no coating is applied to the exposed surfaces; in this case, the

543 residual thickness of the flanges and web (or alternatively loss of thickness) follow a non-

544 linear curve which gradually becomes linear for $t>20$ years. Figures $10(a)$ and 10(b) show

545 that similar results are obtained for the internal main girder element (IMG); however, the

546 predicted reductions of thickness are of much smaller magnitude due to the less aggressive

547 atmospheric environment (C3) considered relevant for these elements, which has a dual

548 benefit: (a) longer coating protection and (b) smaller corrosion rates. The assumption

549 differentiating member exposure in a particular structure was based on surveys indicating the

550 higher susceptibility to atmospheric corrosion of external bridge members, in comparison to

551 their internal counterparts (Tamakoshi et al., 2006). It is important to note that micro-climate

552 effects (e.g. water ingress, inaccessible/hidden parts) can reverse this trend and reveal higher

553 corrosion in internal parts.

\section{$554 \quad 5.2$ Resistance assessment}

555 Performance profiles of deteriorating structures can be evaluated with respect to different serviceability and ultimate limit state criteria, for instance increasing deflections, fatigue, bending resistance, shear resistance, local and global buckling resistances. In this paper, results are presented for the bending, shear and local buckling resistances of the different

559 element types (e.g. EMG, IMG) considering their relative location on the bridge as well as 560 different types of protective coatings.

Figure 11 shows a comparison of bending performance profiles obtained using

562 Equation (8) for EMG and IMG elements considering two different coating types, with the

563 no-coating case also shown. The results indicate that, although the bridge is in a high

564 corrosivity environment, different exposure conditions at element level (due to their relative 565 position on the bridge) cause the bending resistance of external girder (EMG) elements to 
566 deteriorate at a much faster pace relative to the internal main girder (IMG) element. The shear 567 performance profiles (through Equation (9)) in Figure 12 follow a similar trend to the 568 bending results; although in this case, the reduction in shear resistance is slightly more 569 severe. For example, the results in Figures 11 and 12 indicate that at the end of the 30 year 570 maintenance window, the shear and bending resistances of EMG with coating M274 have 571 reduced by more than $12 \%$ and $10 \%$, respectively. Figure 13 shows a comparison of the 572 results for the local buckling performance profiles calculated using Equation (12). These results indicate that the reduction in buckling resistance over time occurs at a much higher

574 rate relatively to the bending and shear resistances. Overall, the results indicate that the

575 deterioration of all performance metrics examined, is moderate for an initial 10 year period,

576 irrespectively of the exposure conditions and coating type, with the reductions being 577 practically within 5\%. However, after this initial period, significant differences in

578 performance are predicted for the examined scenarios. For all performance metrics, the

579 results highlight the significance of the relative location of an element within a bridge, as well

580 as the impact of the protective system, on the progression of deterioration. Similar trends

581 were observed in the results for the stringer (ST) elements, which - as for the IMG elements -

582 are classified as internal elements and are, thus, exposed to lower corrosivity (C3).

\section{$583 \quad 5.3$ General remarks}

584 As discussed earlier, decision making in asset management can be based on condition and/or

585 resistance criteria, which often complement each other. To this end, it is not unlikely to

586 encounter cases where the gradual loss of condition (e.g. due to the breakdown of the

587 protective coating system) is not associated with loss of resistance, at least during the early

588 stages of the deterioration process. As such, considering both types of performance metrics

589 within a common framework can inform risk-based examination and assessment regimes

590 (e.g. Zonta, Zandonini \& Bortot, 2007, Barone, Frangopol \& Soliman, 2014). Furthermore, 
such a framework is an integral part of any life-cycle cost methodology (MAINLINE, 2013c).

Differences between the progression of deterioration in relation to condition and

594 structural performance are often directly related to the exposure conditions, as well as the

595 coating type and its quality. Often, the effect of microclimate associated with specific

596 detailing or other characteristics of a structure can be a significant factor in the evolution of

597 both the condition and structural performance of an element (van de Lindt \& Ahlborn, 2005).

598 In this paper, effects arising from the different atmospheric exposure conditions are only

599 considered; the occurrence and evolution of defects associated with local microclimates

600 caused by unsuitable detailing (e.g. water traps, elements buried in ballast, timber-metal

601 interfaces, etc.) on a structure have not been considered (van de Lindt \& Ahlborn, 2005, Ahn et al., 2013, Khurrama et al., 2014). In practice, it is possible to observe significant localised defects associated with such detailing on structures located in relatively benign exposure conditions and which are otherwise in reasonable condition. Notwithstanding, the results of

605 the case study demonstrate that the proposed framework is sufficiently detailed to

606 differentiate performance predictions based on key external factors and has room for 607 improvement, especially as coating and corrosion models are informed by the collection of

608 field data. Finally, it is relatively straightforward to introduce uncertainty modelling on a

609 number of key variables and to estimate the ensuing statistical properties of the performance 610 profiles, in terms of median or appropriate fractile values.

\section{Conclusions}

612 A methodology has been presented for the development of performance profiles for 613 deteriorating elements in metallic bridges. The gradual breakdown of the protective coating and the effects of atmospheric corrosion have both been modelled, taking into account their 
615 dependency on environmental exposure conditions and a variety of other factors. An

616 approach for long-term changes in pollution or climatic variables has also been proposed. The

617 methodology has been demonstrated through generation of performance profiles for a short-

618 span metallic railway bridge, assumed to be located in a harsh environment. It is shown that it

619 can account for a wide range of exposure conditions, and that it can be adapted so as to cater

620 for micro-climate effects both at inter- and intra-element level. Depending on policy, budget

621 and maintenance constraints, ageing metallic bridges may have to be managed either using

622 condition or resistance criteria. The developed methodology has the flexibility to enable both

623 to be examined, using relatively simple models which have been based on industry manuals

624 and international guidance documents.

\section{Acknowledgements}

626 Part of the work presented in this paper has been undertaken in the course of the FP7

627 European Union funded project MAINLINE (Maintenance, Renewal and Improvement of

628 Rail Transport Infrastructure to reduce Economic and Environmental Impacts). We would

629 like to thank our project partners and, in particular, Brian Bell and David Castlo from

630 Network Rail (UK), for fruitful discussions. The opinions expressed herein are those of the

631 authors only and should not be taken as representative of any of the organizations involved.

\section{References}

633 Aflatooni, M., Chan, T.H.T., Thambiratnam, D.P., \& Thilakarathna I. (2013). Synthetic 634 rating system for railway bridge management. Journal of Civil Structural Health 635 Monitoring, 3(2), 81-91.

636 Ahn, J.H., Kim, I.T., Kainuma, S., \& Lee, M.J. (2013). Residual shear strength of steel plate 637 girder due to web local corrosion. Journal of Constructional Steel Research, 89, 198-

638 212. 
639 Barone, G., Frangopol, D., \& Soliman, M. (2014). Optimization of life-cycle maintenance of

640

641

642

643

644

645

646

647

648

649

650

651

652

653

654

655

656

657

658

659

660

661

662

663

664

665

666

667

668

669

670

671

deteriorating bridges with respect to expected annual failure rate and expected cumulative cost. Journal of Structural Engineering, 140(2), 04013043.

Bell, B. (2007). How the project priorities were established. Sustainable Bridges, Assessment for Future traffic Demands and Longer Lives, Edited by J. Bień, L. Elfgren \& J. Olofsson, Dolnośląskie Wydawnictwo Edukacyjne.

BS EN 22063 (1994). Metallic and other inorganic coatings. Thermal spraying. Zinc, aluminium and their alloys. British Standards Institute, London.

BS EN 1993-1-1. (2005). Eurocode 3: Design of steel structures - Part 1-1: General rules and rules for buildings. British Standards Institute, London.

BS EN ISO. (1998). BS EN ISO 12944-2. Paints and varnishes - corrosion protection of steel structures by protective paint systems - part 2: Classification of environments. British Standards Institute, London.

BS EN ISO (2012b). BS EN ISO 9224:2012 - Corrosion of metals and alloys - Corrosivity of atmospheres - Classification, determination and estimation. British Standards Institute, London.

BS EN ISO (2012a). BS EN ISO 9223:2012 - Corrosion of metals and alloys - Corrosivity of atmospheres - Guiding values for the corrosivity categories. British Standards Institute, London.

CORUS (2004). The prevention of corrosion on structural steelwork. Corus Construction \& Industrial, UK.

CORUS (2005). Corrosion protection of steel bridges. Corus Construction \& Industrial, UK.

Chang, L.M., Georgy, M.E., \& Abdelrazig, Y. (2000). Warranting quality of steel bridge coating. ASCE Journal of Construction Engineering and Management, 126(5), 374380.

Czarnecki, A.A., \& Nowak, A.S. (2008). Time-variant reliability profiles for steel girder bridges. Structural Safety, 30, 49-64.

de Wit, J.H.W., van der Weijde, D.H., \& Ferrari, G. (2011). Organic coatings. In: Corrosion Mechanisms in Theory and Practice, 3rd Edition, Marcus P. (Ed), CRC Press, 863905.

Feliu, S., Morcillo, M., \& Feliu, S. Jr. (1993). The prediction of atmospheric corrosion from meteorological and pollution parameters - I. Annual corrosion. Corrosion Science, 34(3), 403-414. 
672 Gascoyne, A., \& Bottomley D. (1995). Atmospheric corrosion rates of railway bridge

673

674

675

676

677

678

679

680

681

682

683

684

685

686

687

688

689

690

691

692

693

694

695

696

697

698

699

700

701

702

703

704 structures. Report No. LR-MSU-084, Issued by Scientifics for the British Rail Research, British Railways Board, UK.

Greenfield, D., \& Scantlebury, D. (2000). The protective action of organic coatings on steel: a review. The Journal of Corrosion Science and Engineering, 3, Paper 5.

Hare, C.H. (2006). Corrosion and its control by coatings. In: Coatings Technology Handbook, Taylor \& Francis Group, 102, 1-9.

Hutchins, J.S., \& McKenzie, M. (1973). Characterisation of bridge locations by corrosion and environmental measurements - first year results. Report No.LR550, Transport and Road Research Laboratory. UK.

Imam, B.M., \& Chryssanthopoulos, M.K. (2012). Causes and consequences of metallic bridge failures. Structural Engineering International, 22(1), 93-98.

Itoh, Y., \& Kim, I.T. (2006). Accelerated cyclic corrosion testing of structural steels and its application to assess steel bridge coatings. Anti-Corrosion Methods and Materials, 53(6), 374-381.

Jin, N.H., Chryssanthopoulos, M.K., \& Parke G.A.R. (2007). A probabilistic methodology for sustainable bridge management. Proceedings of the $5^{\text {th }}$ International Workshop on Life-Cycle Cost Analysis and Design of Civil Infrastructure Systems. Seoul, South Korea, 181-189.

Kayser, J.R., \& Nowak, A.J. (1989). Capacity loss due to corrosion in steel-girder bridges. Journal of Structural Engineering, 115(6), 1525-1537.

Keijman, J.M. (1999). Inorganic and organic coatings - the difference In: PCE' 99 Conference: Achieving quality in coatings work: the 21st Century challenge. Brighton, UK.

Khurrama, N., Sasakia, E., Kihirab, H., Katsuchia, H., \& Yamada, H. (2014). Analytical demonstrations to assess residual bearing capacities of steel plate girder ends with stiffeners damaged by corrosion. Structure and Infrastructure Engineering, 10(1), 6979.

Kim, I.T., \& Itoh, Y. (2007). Accelerated exposure tests as evaluation tool for estimating life of organic coatings on steel bridges. Corrosion Engineering, Science and Technology, $42(3), 242-252$.

Klinesmith, D.E., McCuen, R.H., \& Albrecht, P. (2007). Effect of environmental conditions on corrosion rates. Journal of Materials in Civil Engineering, 19(2), 121-129. 
705

706

707

708

709

710

711

712

713

714

715

716

717

718

719

720

721

722

723

724

725

726

727

728

729

730

731

732

733

734

735

736

737

Kuroda, S., Kawakita, J., \& Takemoto, M. (2006). An 18-year exposure test of thermalsprayed $\mathrm{Zn}, \mathrm{Al}$, and $\mathrm{Zn}-\mathrm{Al}$ coatings in marine environments. Corrosion, 62(7), 635647

Landolfo, R., Cascini, L., Portioli, F. (2010). Modeling of metal structure corrosion damage: a state of the art report. Sustainability, 2, 2163-2175.

MAINLINE (2013a). Deliverable 2.2: Degradation and intervention modelling techniques, Work Package 2, MAINLINE (Maintenance, Renewal and Improvement of Rail Transport Infrastructure to reduce Economic and Environmental Impacts) Consortium (www.mainline-project.eu).

MAINLINE (2013b). Deliverable 2.3: Time-variant Performance Profiles for Life-Cycle Cost and Life-Cycle Analysis, Work Package 2, MAINLINE (Maintenance, Renewal and Improvement of Rail Transport Infrastructure to reduce Economic and Environmental Impacts) Consortium (www.mainline-project.eu).

MAINLINE (2013c). Deliverable 5.4: Proposed methodology for a Life Cycle Assessment Tool (LCAT), Work Package 5, MAINLINE (Maintenance, Renewal and Improvement of Rail Transport Infrastructure to reduce Economic and Environmental Impacts) Consortium (www.mainline-project.eu).

MAINLINE (2014). Deliverable 2.4: Field-validated Performance Profiles, Work Package 2, MAINLINE (Maintenance, Renewal and Improvement of Rail Transport Infrastructure to reduce Economic and Environmental Impacts) Consortium (www.mainline-project.eu).

Nguyen, T., Hubbard, J.B., \& Pommersheim, J.M. (1996). Unified model for the degradation of organic coatings on steel in a neutral electrolyte. Journal of Coatings Technology, 68 (no. 855), 45-56.

NR (2009a). NR/L3/CIV/002: The use of protective coatings and sealants. Guidance Note. Network Rail, UK.

NR (2009b). NR/L3/CIV/039: Level 3 - Specification for the assessment and certification of protective coatings and sealants. Network Rail, UK.

NR (2009c). NR/L3/CIV/040: Level 3 - Specification for the use of protective coating systems. Network Rail, UK.

Pommersheim, J.M., Nguyen, T., Zhang, Z., \& Hubbard, J.B. (1994). Degradation of organic coatings on steel: mathematical models and predictions. Progress in Organic Coatings, 25, 23-41. 
Prucz, Z., \& Kulicki, J.M. (1998). Accounting for effects of corrosion section loss in steel bridges. Transportation Research Record, 1624, 101-109.

Salas, O., de Tincon, O.T., Rojas, D., Tosaya, A., Romero, N., Sanchez, M., \& Campos, W. (2012). Six-year evaluation of thermal-sprayed coating of $\mathrm{Zn} / \mathrm{Al}$ in tropical marine environments. International Journal of Corrosion, 2012, Article ID 318279.

Sharifi, Y., \& Paik J.K. (2011). Ultimate strength reliability analysis of corroded steel-box girder bridges. Thin-Walled Structures, 49, 157-166.

Sorensen, P.A., Kiil, S., Dam-Jojansen, K., \& Weinell, C.E. (2009). Anticorrosive coatings: a review. Journal of Coating Technology, 6(2), 135-176.

Tamakoshi, T., Yoshida, Y., Sakai, Y., \& Fukunaga S. (2006). Analysis of damage occurring in steel plate girder bridges on national roads in Japan. In: $22^{\text {nd }}$ US-Japan Bridge Engineering Workshop. Seattle. WA.

Timoshenko, S.P. (1964). Theory of plates and shells. McGraw Hill, London.

Wardhana, K., \& Hadipriono, F.C. (2003). Analysis of recent bridge failures in the United States. Journal of Performance of Constructed Facilities, 17(3), 144-150.

van de Lindt, J.W., \& Ahlborn, T.M. (2005). Development of steel beam end deterioration guidelines. Final Report, Michigan Tech, Research Report RC-1454, USA.

Zonta, D., Zandonini, R., \& Bortot, F. (2007). A reliability-based bridge management concept. Structure and Infrastructure Engineering, 3(3), 215-235.

7

(1)


764 Table 1: Description of atmospheric corrosivity categories and corresponding corrosion rates

765 (BS EN ISO 2012a).

\begin{tabular}{ll}
$\begin{array}{l}\text { Corrosivity } \\
\text { category }\end{array}$ & Description \\
\hline C1 & Very low corrosivity: Dry or cold zone, atmospheric environment with \\
& very low pollution and time of wetness, e.g. certain deserts, Central \\
& Arctic/Antarctica. \\
& Low corrosivity: Temperate zone, atmospheric environment with low \\
C2 & pollution $\left(\mathrm{SO}_{2}<5 \mu \mathrm{g} / \mathrm{m}^{3}\right)$, e.g. rural areas, small towns. Dry or cold \\
& zone, atmospheric environment with short time of wetness, e.g. deserts, \\
& subarctic areas.
\end{tabular}

C3 Medium corrosivity: Temperate zone, atmospheric environment with medium pollution ( $\mathrm{SO}_{2}: 5 \mu \mathrm{g} / \mathrm{m}^{2}$ to $30 \mu \mathrm{g} / \mathrm{m}^{3}$ ) or some effect of chlorides, e.g. urban areas, coastal areas with low deposition of chlorides. Subtropical and tropical zone, atmosphere with low pollution.

C4 High corrosivity: Temperate zone, atmospheric environment with high pollution ( $\mathrm{SO}_{2}: 30 \mu \mathrm{g} / \mathrm{m}^{3}$ to $90 \mu \mathrm{g} / \mathrm{m}^{3}$ ) or substantial effect of chlorides, e.g. polluted urban areas, industrial areas, coastal areas without spray of salt water or, exposure to effect of de-icing salts. Subtropical and tropical zone, atmosphere with medium pollution.

C5 Very high corrosivity: Temperate and subtropical zone, atmospheric environment with very high pollution ( $\mathrm{SO}_{2}: 90 \mu \mathrm{g} / \mathrm{m}^{3}$ to $250 \mu \mathrm{g} / \mathrm{m}^{3}$ ) and/or significant effect of chlorides, e.g. industrial areas, coastal areas, sheltered positions on coastline.

CX Extreme corrosivity: Subtropical and tropical zone (very high time of wetness), atmospheric environment with high $\mathrm{SO}_{2}$ pollution (higher than $250 \mu \mathrm{g} / \mathrm{m}^{3}$ ) including accompanying and production factors and/or strong effect of chlorides, e.g. extreme industrial areas, coastal and offshore areas, occasional contact with salt spray.

Notes: ${ }^{1}$ Corrosion rates correspond to the first year of exposure. 
767 Table 2. Description and expected service life of protective coatings (NR 2009a and b).

Coating Description

Expected

$\begin{array}{lll}\text { system [for more details see (NR 2009a, b)] life, } \boldsymbol{T}_{\boldsymbol{L}} & \end{array}$

name

(years)

M27.4 Protective system using bitumen. $1^{\text {st }}$ layer: surface tolerant epoxy

$5-7$

primer (min dft $100 \mu \mathrm{m}$. Intermediate coat: gelled bituminous

solution - aluminium tinted (min dft $200 \mu \mathrm{m}$ ). Topcoat: gelled

bituminous solution - black finish with min dft $200 \mu \mathrm{m}$.

M21 Coating using epoxy glass flake. $1^{\text {st }}$ layer: epoxy blast primer with

min dft $25 \mu \mathrm{m}$. Intermediate layer: epoxy glass flake intermediate

coat with min $\mathrm{dft} 40 \mu \mathrm{m}$ and for layer $\mathrm{C}$ select among the following

(min dft $50 \mu \mathrm{m}$ ): anti-graffiti paint or polyurethane coloured finish

or acrylic urethane topcoat or polysiloxane topcoat.

768

769

770

771

772

773

774

775

776

777

778

779

780

781

782 
Table 3. Corrosion model classification.

\section{Level Description \\ Comments}

Empirical models. Effect of all influencing

1 factors taken into account through model constants

Empirical models which relate the rate of

2 corrosion to specific exposure variables, also known as dose response functions (DRF).

3

Theoretical models involving simulation techniques to predict airflow patterns and pollutant mass transfer on exposed surfaces
Model coefficients are associated with very high uncertainty. Statistical properties may not be reliable due to inhomogeneous samples. Questionable model transferability.

Reliance on spatial data for atmospheric pollutants and climatic parameters. Potentially suitable for probabilistic analysis, though uncertainty modelling largely untested.

Heavy reliance on modelling assumptions. Complex uncertainty modelling, currently lack of input data at desired granularity level.

784

785

786

787

788

789

790

791

792

793

794

795

796

797

798

799

800 
802 Table 4. Scenarios considered in the case study

803

804

\begin{tabular}{|c|c|c|c|c|}
\hline \multirow[b]{2}{*}{$\begin{array}{c}\text { Element } \\
\text { type }^{1}\end{array}$} & \multicolumn{2}{|c|}{ Exposure classification $^{2}$} & \multicolumn{2}{|c|}{ Coating } \\
\hline & $\begin{array}{c}\text { Bridge } \\
\text { level }\end{array}$ & $\begin{array}{c}\text { Element } \\
\text { level }\end{array}$ & $\begin{array}{l}\text { Coating } \\
\text { type }\end{array}$ & $\begin{array}{c}\text { Service life }^{3} \text {, } \\
T_{L} \text { (years) }\end{array}$ \\
\hline
\end{tabular}

805

IMG C5 C3 No Coating -

806

$\begin{array}{lllll}\text { IMG } & \text { C5 } & \text { C3 } & \text { M27.4 }\end{array}$

$\begin{array}{lllll}\mathrm{IMG} & \mathrm{C} 5 & \mathrm{C} 3 & \mathrm{M} 21\end{array}$

807

EMG C5 $\quad$ C5 No Coating -

$\begin{array}{lllll}\text { EMG } & \text { C5 } & \text { C5 } & \text { M27.4 }\end{array}$

808

$\begin{array}{lllll}\mathrm{EMG} & \mathrm{C} 5 & \mathrm{C} 5 & \mathrm{M} 21 & 18\end{array}$

$\begin{array}{llll}\text { ST } & \text { C5 } & \text { C3 No Coating }\end{array}$

$\begin{array}{llllll}809 & \text { ST } & \text { C5 } & \text { C3 } & \text { M21 } & 20\end{array}$
classification in line with BS EN ISO 9223, ${ }^{3}$ Expected coating life based on NR/GN/CIV/002. Coating specifications are given in Table 2.

811

812

813

814

815

816

817

818

819

820

821

822

823

824

825 
$826 \quad$ Figures

827

828

829

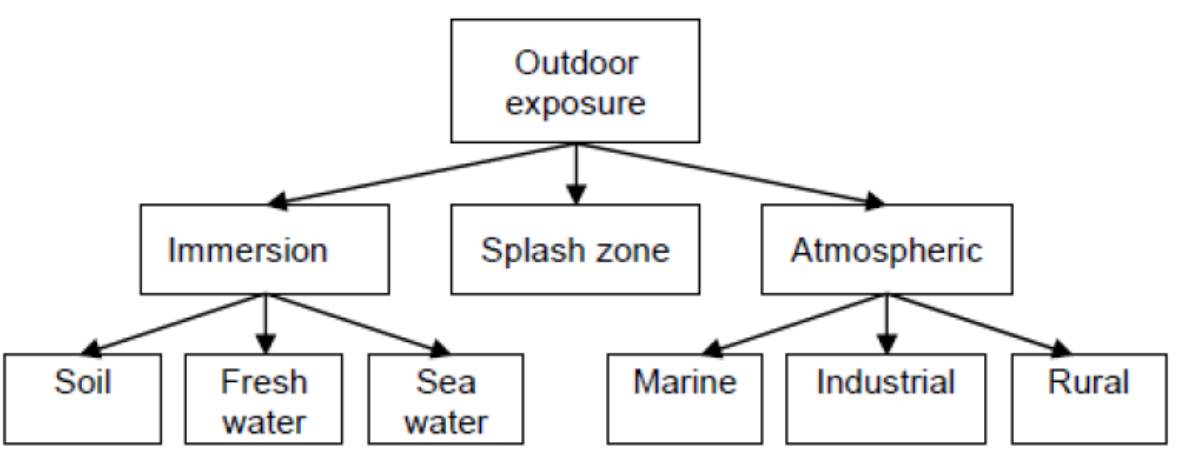

830

831

Figure 1

832

833

834

835

836

837

838

839

840

841

842

843

844

845

846 


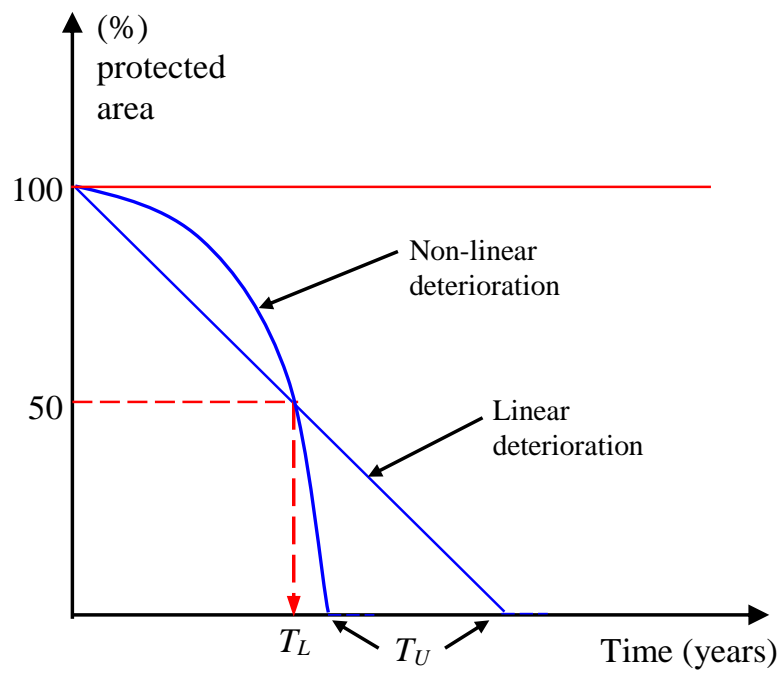

856

857

858

Figure 2

859

860

861

862

863

864

865

866

867

868

869

870

871

872 
873

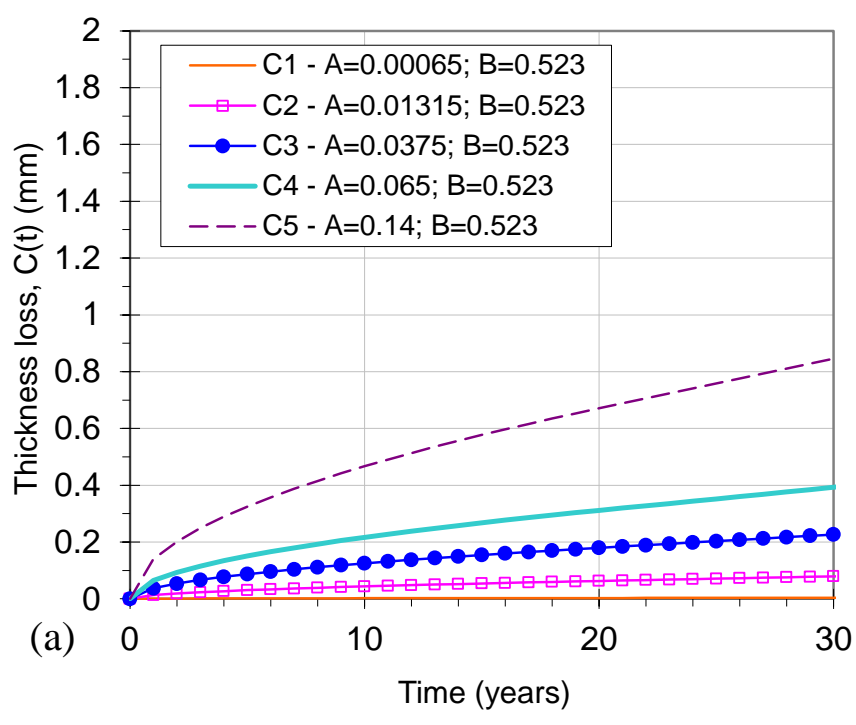

874

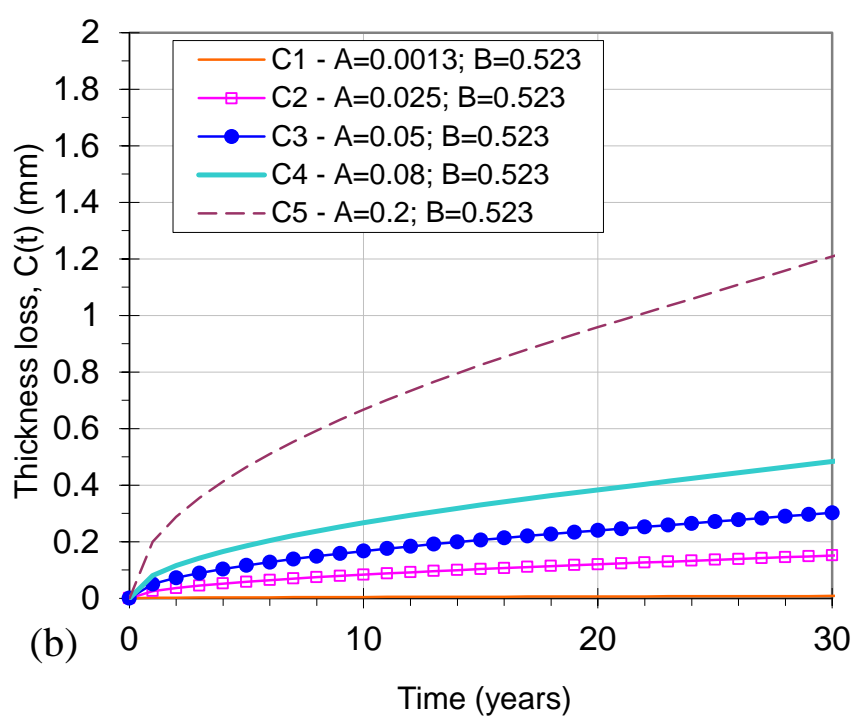

875

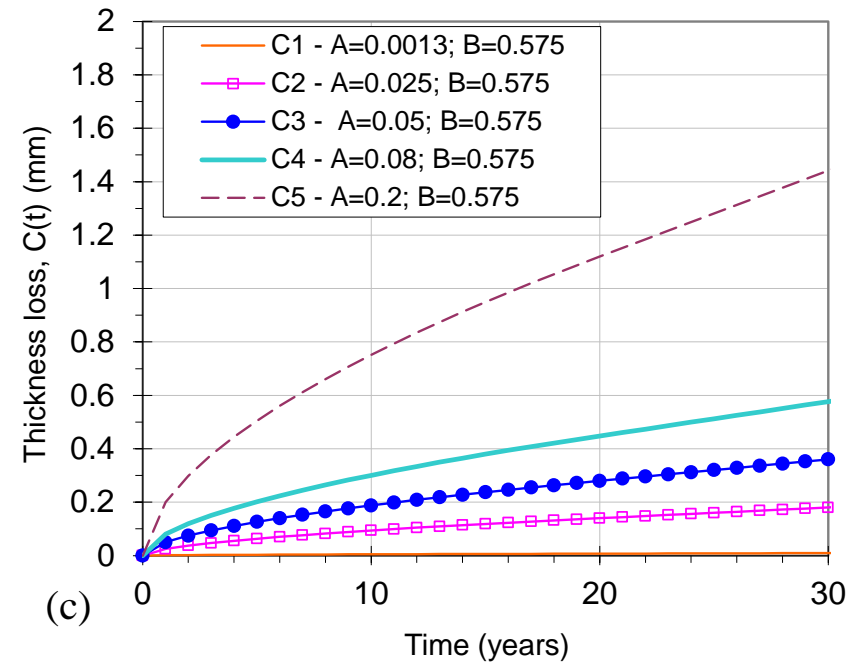

Figure 3 


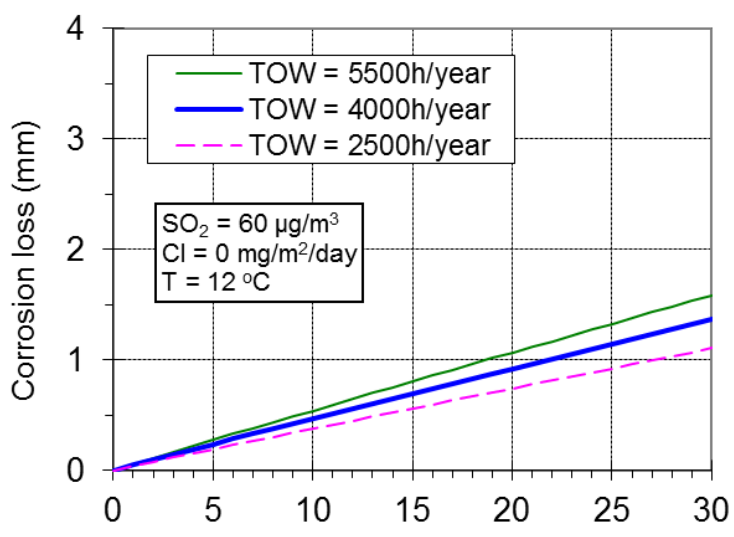

(a)

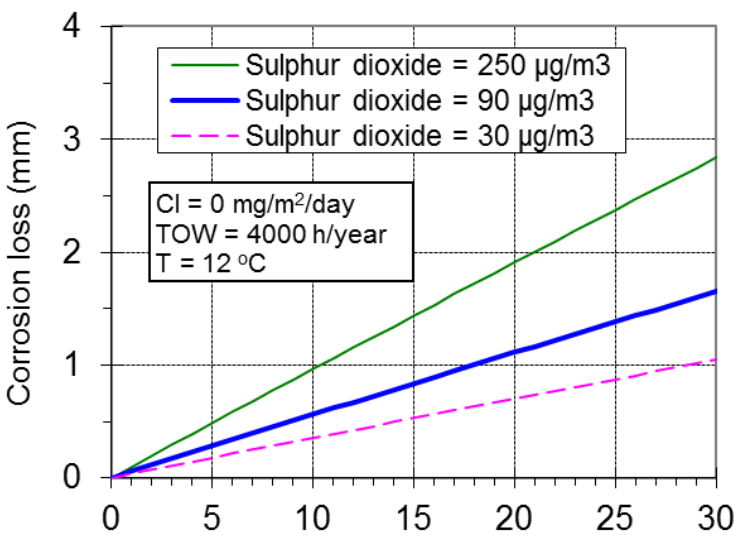

(c)

Time (years)

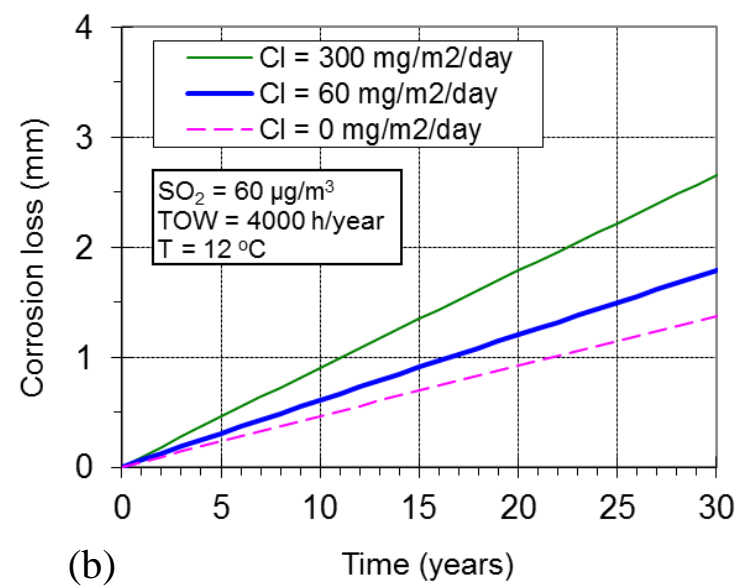

880

881

882

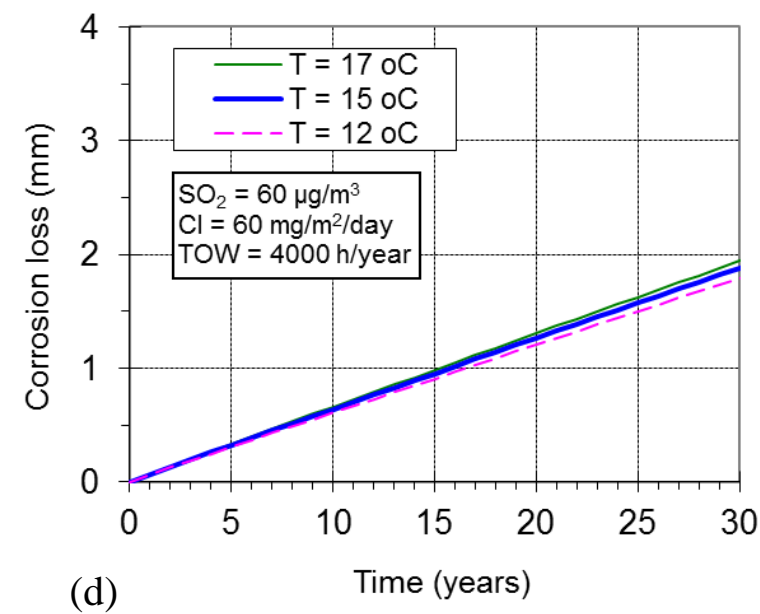

(d)

Time (years)

Figure 4

883

884

885

886

887

888

889

890

891 
892

893

894

895

896

897

898

899

900

901

902

903

904

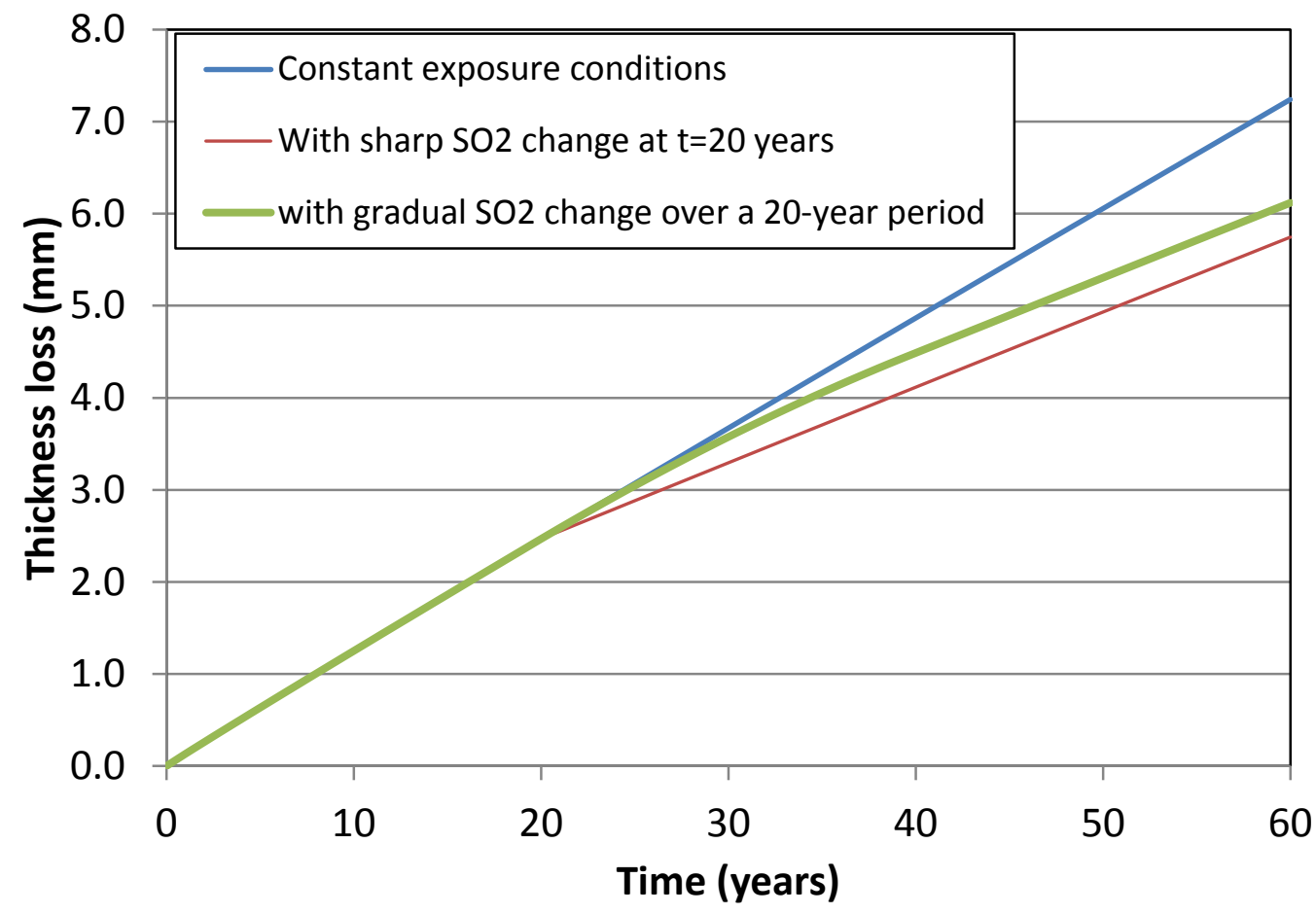

905

Time (years)

906

907

Figure 5

908

909

910

911

912

913

914

915

916

917 


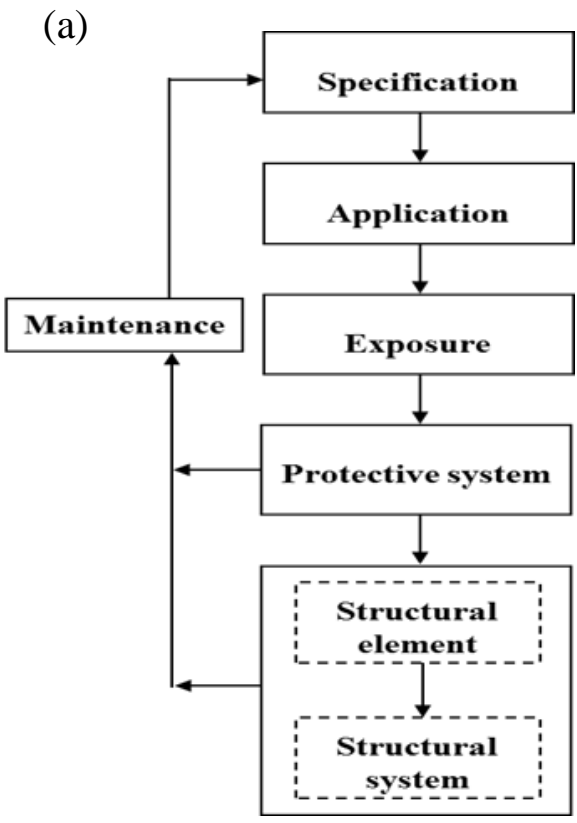

921

922

923

924

925

926

927

928

929

930

931

932

933

934

935 (b)

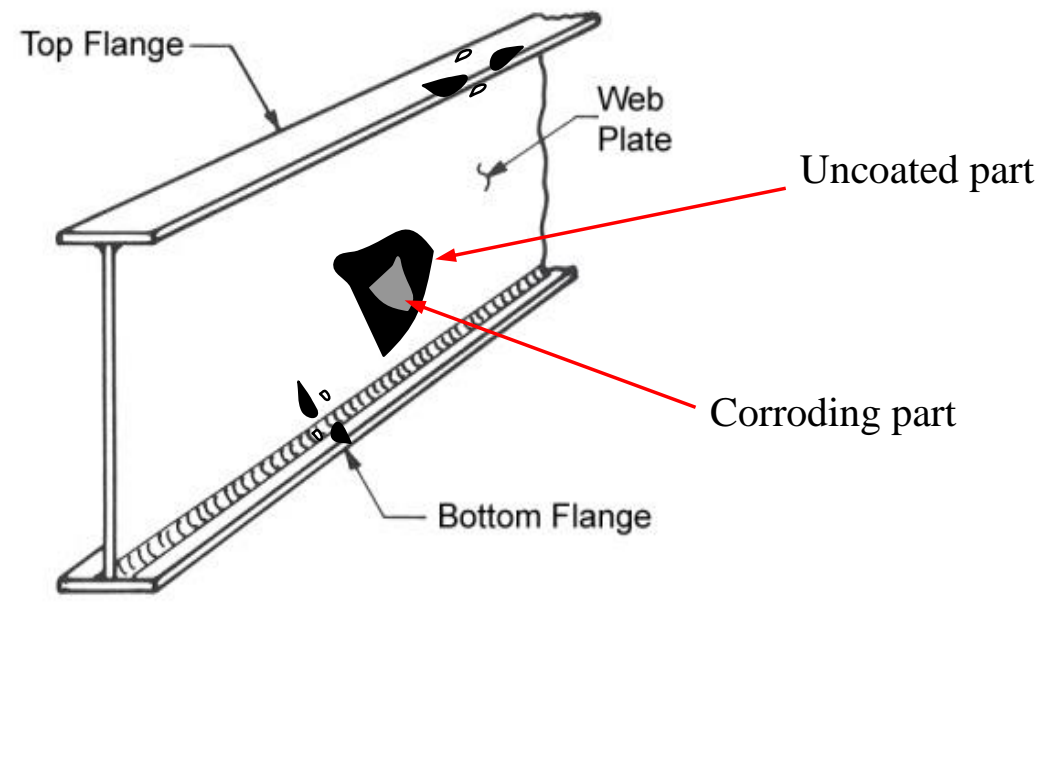

Figure 6 
936

937

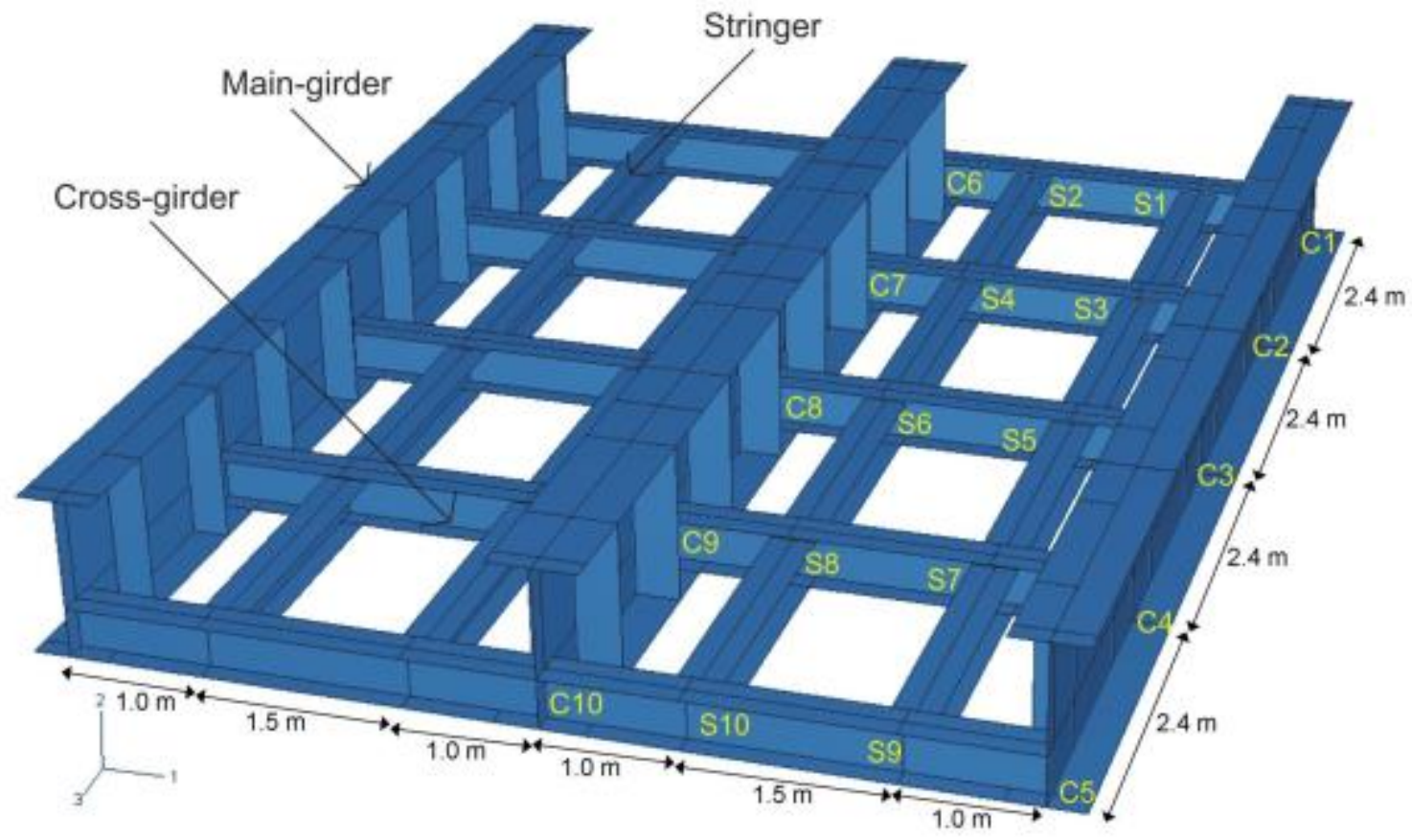

938

939

940

Figure 7

941

942

943

944

945

946

947

948

949

950

951 
954

955

956

957

958

959

960

961

962

963

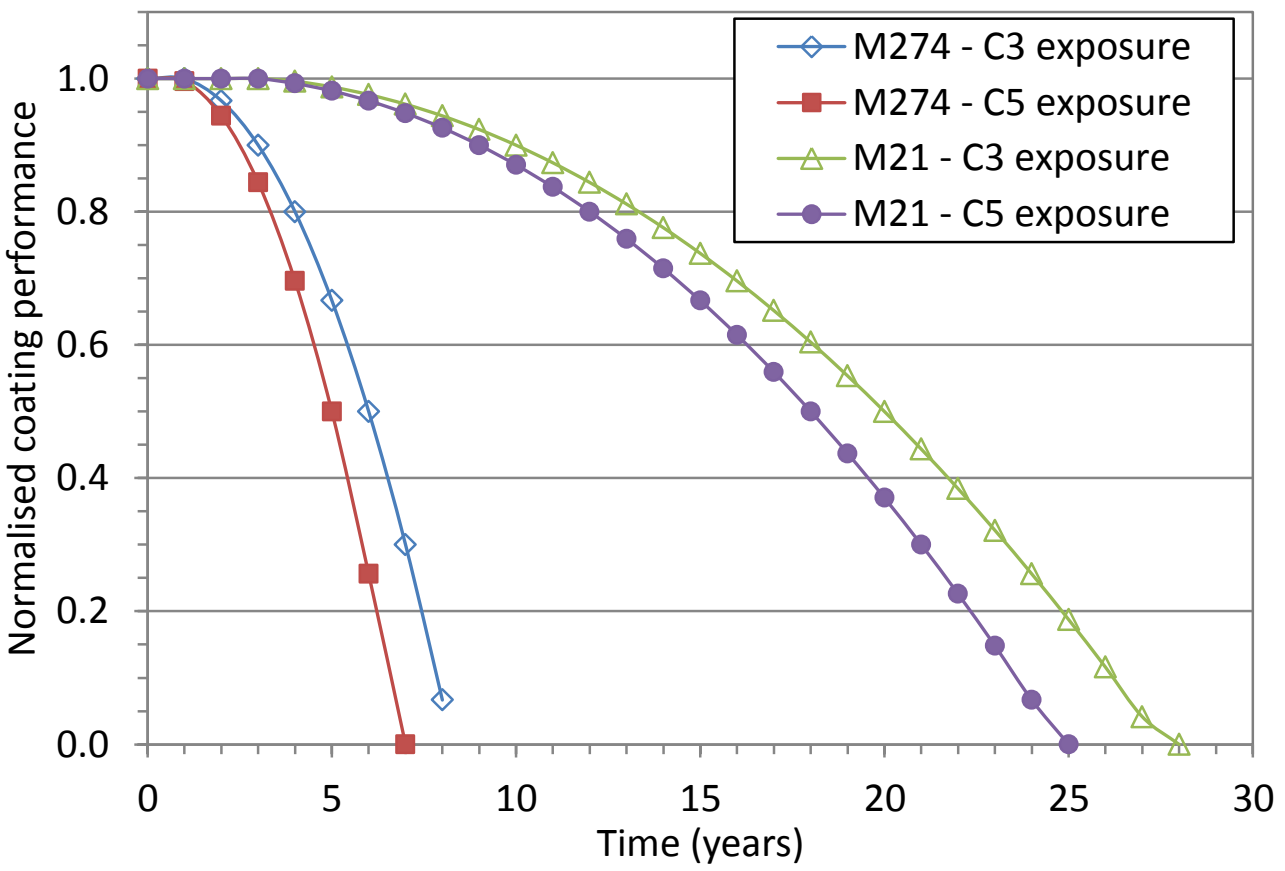

964

965

Figure 8

966

967

968

969

970

971

972

973

974

975

976 
979

980

981

982

983

984

985

(a)

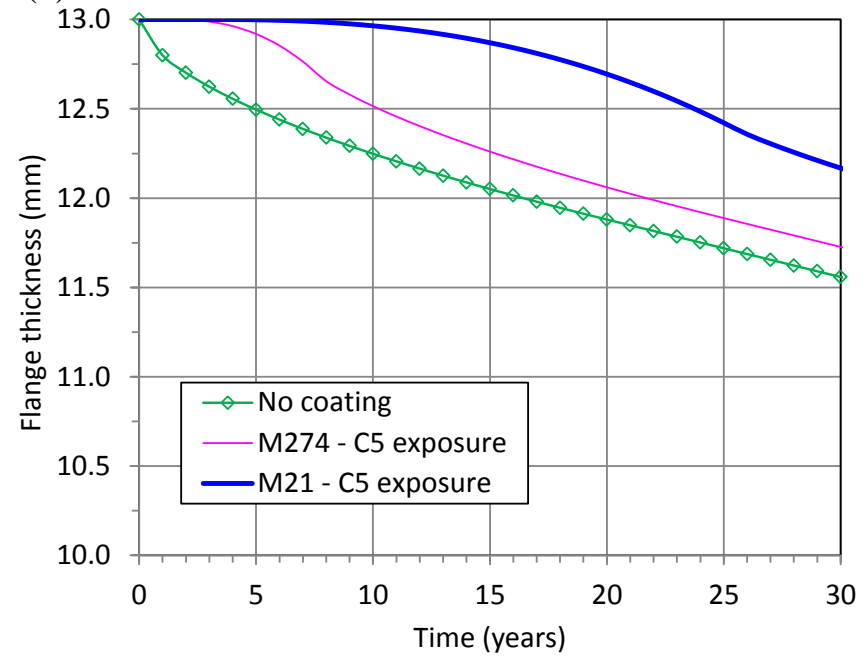

986

987

988

989

990

991

992

993

994

995

996

997

998

999

1000

1001

Figure 9 (b)

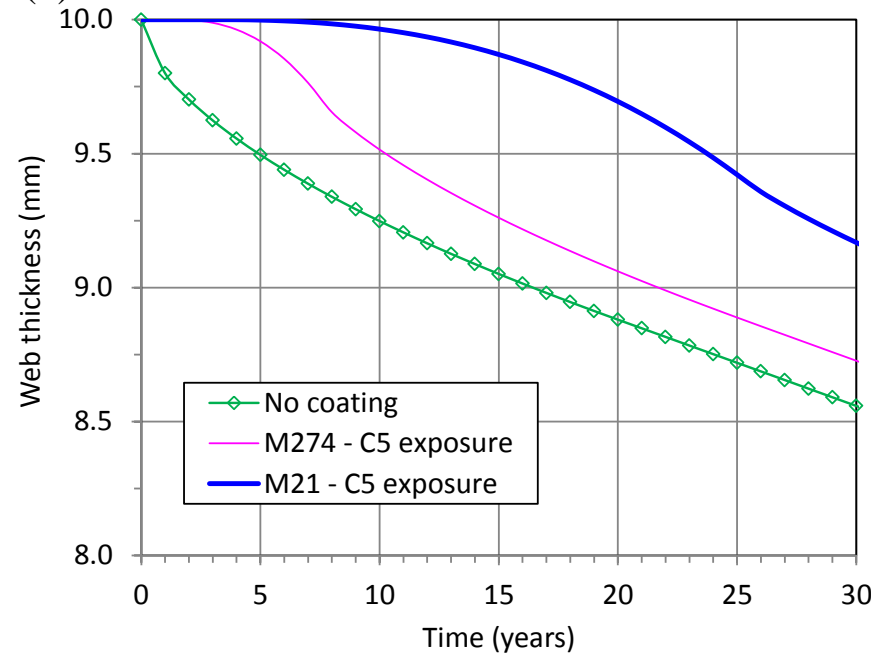


1003

1004

1005

(a)

1006

1007

1008

1009

1010

1011

1012

1013

1014

1015

1016

1017

1018

1019

1020

1021

1022

1023

1024

1025

1026

Figure 10

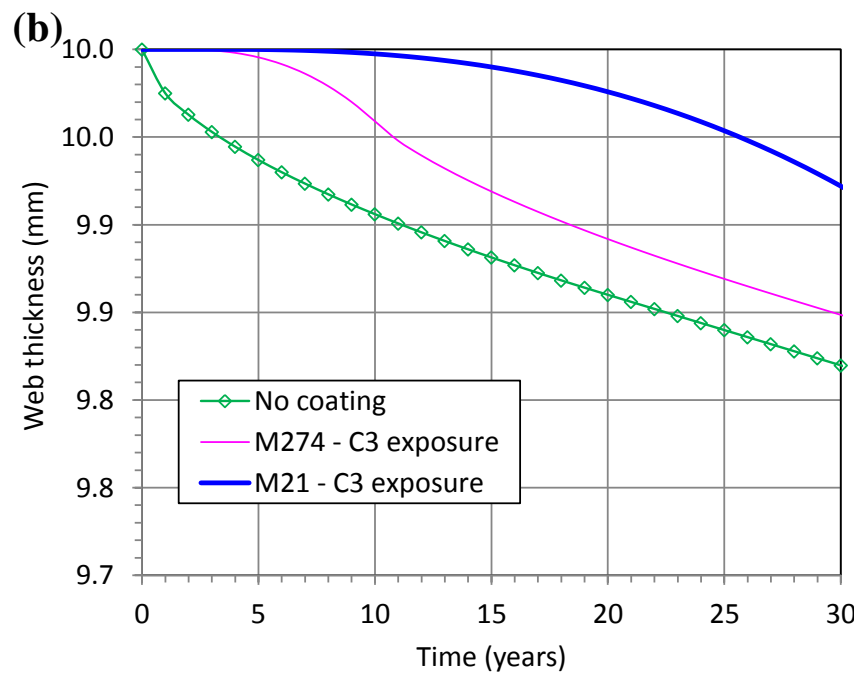


1029

1030

1031

1032

1033

1034

1035

1036

1037

1038

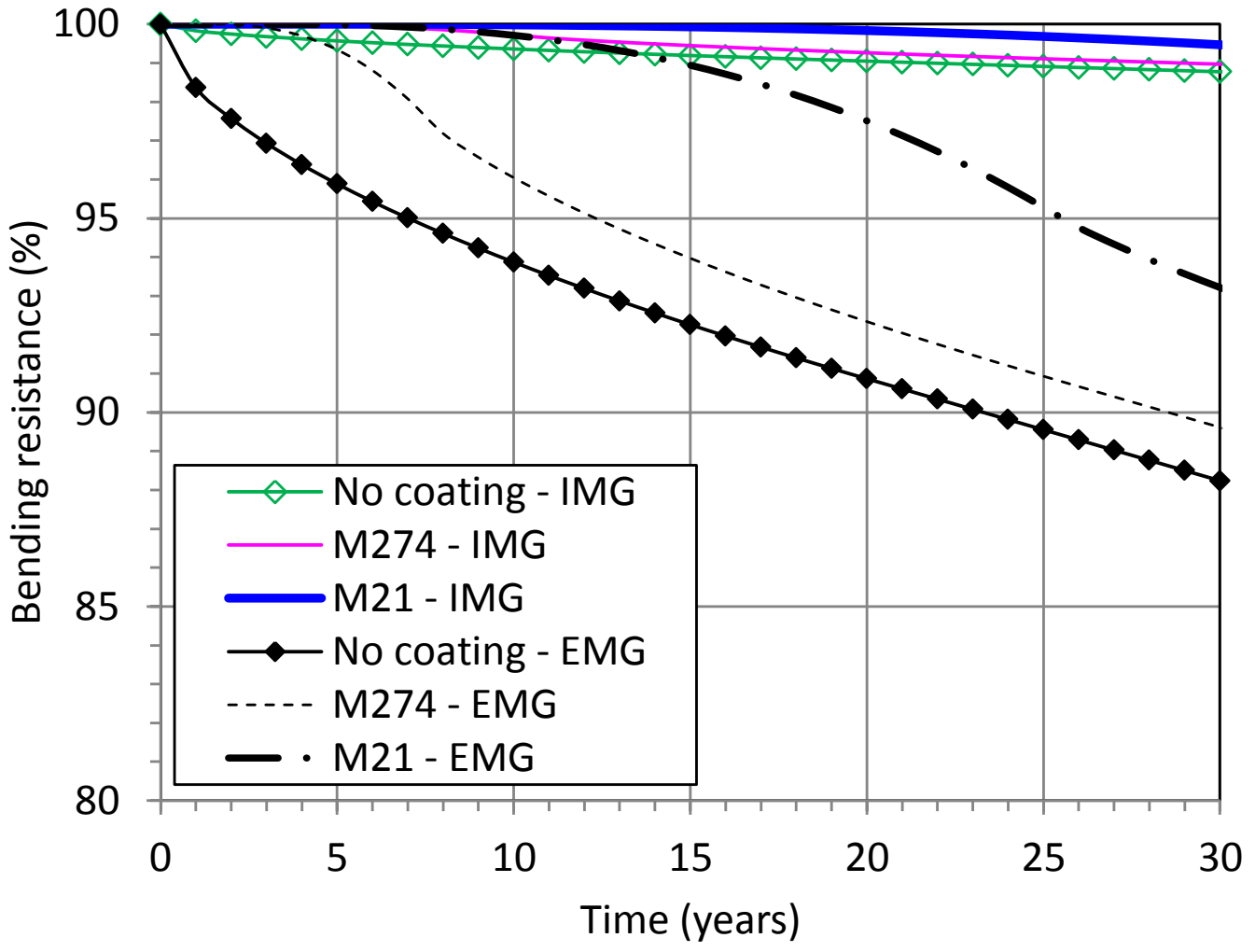

1040

1041

1042

1043

1044

Figure 11

1045

1046

1047

1048

1049

1050

1051 
1053

1054

1055

1056

1057

1058

1059

1060

1061

1062

1063

1064

1065

1066

1067

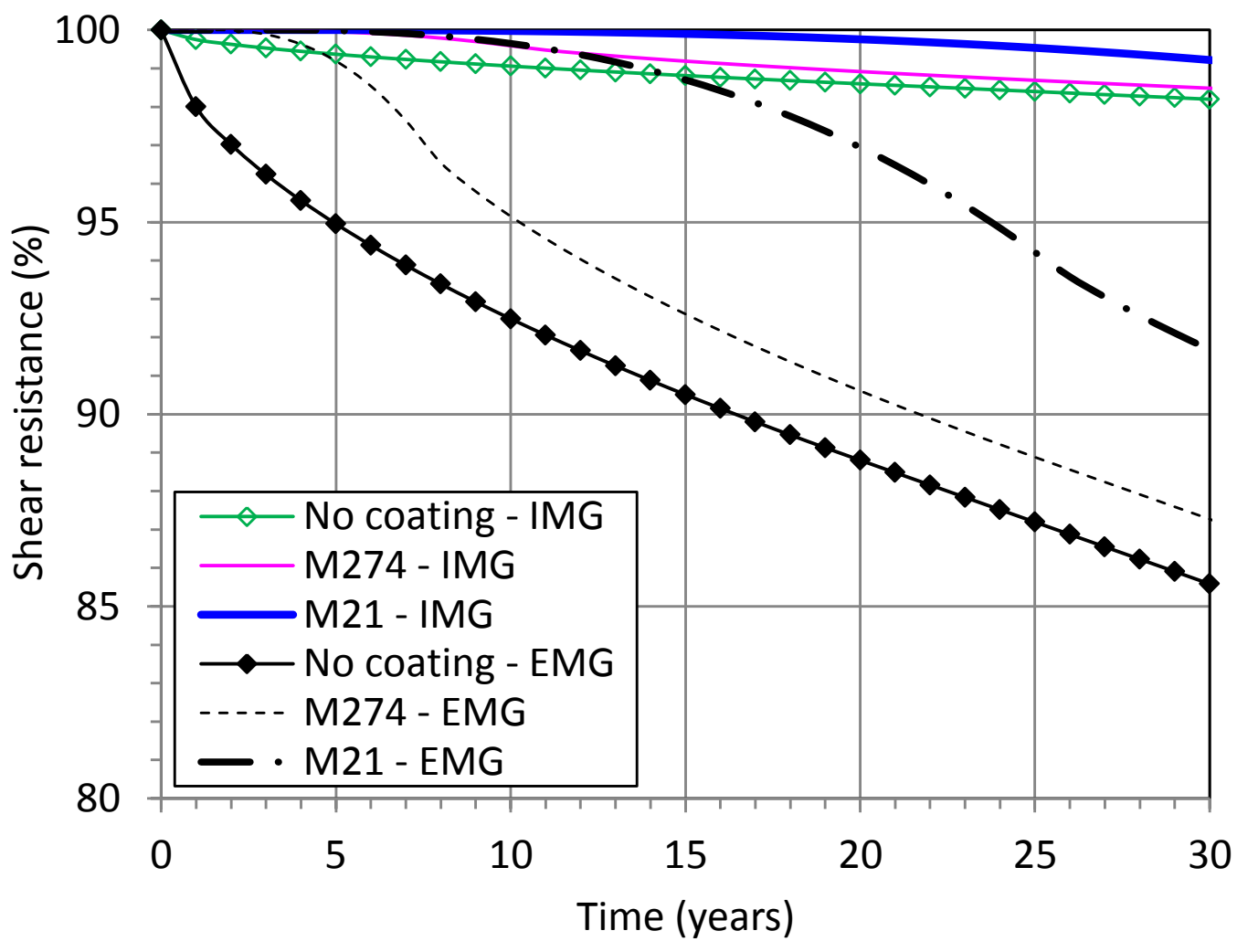

1068

1069

Figure 12

1070

1071

1072

1073

1074

1075

1076 
1078

1079

1080

1081

1082

1083

1084

1085

1086

1087

1088

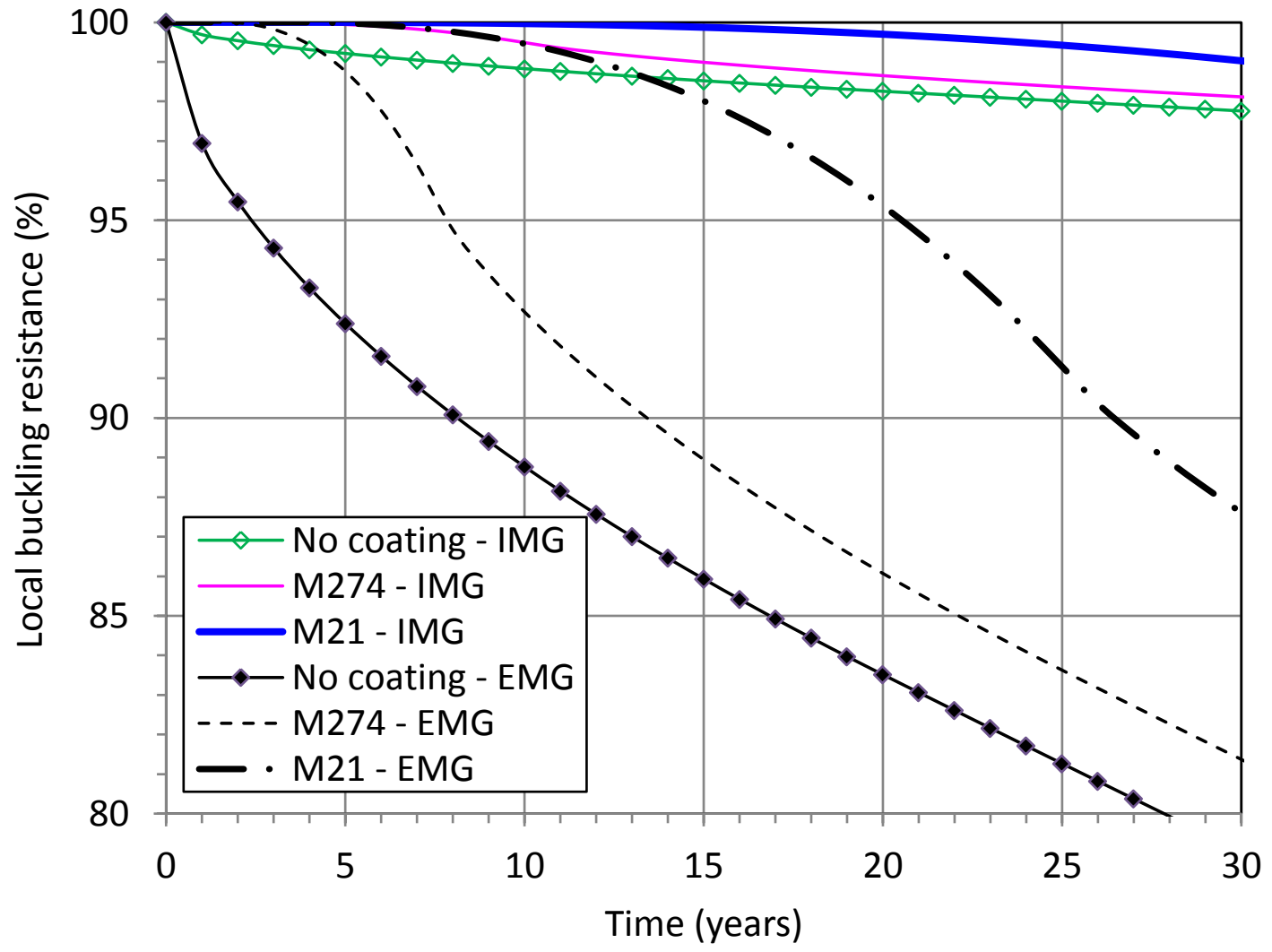

1090

1091

1092

Figure 13

1093

1094

1095

1096

1097

1098

1099

1100

1101 
1102 Figure captions

1103 Fig. 1: Outdoor exposure environments (Sorensen et al., 2009).

1104 Fig. 2: Level 1 deterioration model for coating system performance.

1105 Fig. 3: Thickness loss over time predicted using Equations 2 and 3 and Table 1; (a) mid-range 1106 values for $\mathrm{A} ; \mathrm{B}=0.523$, (b) upper limits for $\mathrm{A} ; \mathrm{B}=0.523$ and (c) upper limits for $\mathrm{A} ; \mathrm{B}$ $1107 \quad=0.575$.

1108 Fig. 4: Effect of varying climatic and atmospheric pollutant parameters on the corrosion losses with time, predicted using Equation (5); (a) time-of-wetness (TOW), (b) Cl

1110 deposition rate, (c) $\mathrm{SO}_{2}$ concentration and (d) temperature.

1111 Fig. 5: Thickness loss over time under changing exposure conditions.

1112 Fig. 6: Performance modelling framework (a) factors under consideration (b) progression of deterioration on coated metallic surfaces.

1114 Fig. 7: Schematic view of the short-span railway bridge.

1115 Fig. 8: Performance profiles of two coating systems under different exposure conditions.

1116 Fig. 9: Residual thickness profiles for EMG elements under C5 exposure conditions: (a)

$1117 \quad$ flanges thickness and (b) web thickness.

1118 Fig. 10: Residual thickness profiles for IMG elements under C3 exposure conditions: (a)

1119 flanges thickness and (b) web thickness.

1120 Fig. 11: Bending resistance profiles for EMG and IMG elements under, respectively, C5 and C3 exposure conditions.

1122 Fig. 12: Shear resistance profiles for EMG and IMG elements under, respectively, C5 and C3 exposure conditions.

1124 Fig. 13: Local buckling resistance profiles for EMG and IMG elements under, respectively, $\mathrm{C} 5$ and $\mathrm{C} 3$ exposure conditions. 